\title{
RegT-Band: a tropical band version of RegCM4
}

\author{
E. Coppola*, F. Giorgi, L. Mariotti, X. Bi
}

Earth System Physics Section, Abdus Salam International Centre for Theoretical Physics, Strada Costiera 11, 34151 Trieste, Italy

\begin{abstract}
We present RegT-Band, a tropical band version of the regional climate model RegCM4, and analyze a 5 yr simulation for the period 1998-2002 with observed sea-surface temperature (SST) and lateral boundary condition forcing. The domain extends from $50^{\circ} \mathrm{S}$ to $50^{\circ} \mathrm{N}$ and covers the entire tropics at a grid spacing of about $39 \mathrm{~km}$, i.e. it includes lateral boundary forcing only at the southern and northern boundaries. RegT-Band captures the basic features of the tropical circulation and associated precipitation patterns. The most noticeable model deficiencies occur over the Indian Ocean, where the convective parameterization used presents some problems. Monsoon precipitation patterns over different regions are captured, although the model shows a tendency for an early onset of the Indian and northern Australian monsoon. The model also captures the ENSO signal on the precipitation anomaly patterns for the 1998 El Niño event compared to the 2000 La Niña event. Although further testing is needed, this simulation shows encouraging results towards the use of RegT-Band for the study of tropical climate processes.
\end{abstract}

KEY WORDS: Regional climate $\cdot$ Monsoon regions $\cdot$ ENSO response

\section{INTRODUCTION}

A new version of the Abdus Salam International Centre for Theoretical Physics (ICTP) regional climate modeling system, RegCM4, has recently been developed and released for community use (Giorgi et al. 2012, this Special). One of the innovative options developed within the RegCM4 system is the possibility to run it in a tropical band configuration (hereafter referred to as RegT-Band). To date, only a few regional climate models (RCMs) have been run in such a configuration (Tulich et al. 2010, Murthi et al. 2011, Ray et al. 2011). RegT-Band offers the opportunity to explore a range of processes related to tropical climate interactions and to assess the performance of given physics parameterizations in a wide range of climate contexts. For example important intraseasonal variability phenomena, such as the eastward propagating Madden-Julian Oscillation (Madden \& Julian 1972), or convectively coupled Kelvin waves, can be studied only in a global tropical set-up. In addition, the ENSO-monsoon teleconnections can be properly simulated as long as they are mainly governed by tropical wave responses such as, for example, the ENSO-Indian monsoon and ENSO-West African monsoon relations (e.g. Ju \& Slingo 1995, Giannini et al. 2003). Such teleconnections are typically difficult to model with a conventional regional model set-up because of the large Pacific region to be included. In addition, climate change signals in tropical regions may also depend on the tropical SST changes, and influences on the monsoons may be better simulated if the domain includes the tropical Pacific and other tropical basins (e.g. Rauscher et al. 2010, Mariotti et al. 2011).

In addition, when run in a tropical band configuration due to the large size of the domain, an RCM is less strongly influenced by lateral boundary condition forcing than in its typical limited area domain configuration. This offers 2 additional opportunities. On the one hand, model performance reflects its ability to simulate large-scale circulations and processes not strongly forced by the lateral meteorological boundary conditions, as in traditional RCM experi- 
ments. In this regard it could be argued that the tropical band RCM might behave more as a global model than as a regional one. On the other hand, the comparison with results from corresponding traditional RCM experiments over domains encompassed by the tropical band can provide useful information on the effects of the lateral boundary forcing in limited area domains.

It is thus clear that the capability of running in tropical band mode provides an important added value for an RCM system. From a technical point of view, the implementation of the tropical band configuration is relatively straightforward, at least within horizontal grid systems such as that of the RegCM4 (see Section 2), and it does not present particularly complex technical problems. Based on these considerations we developed the RegT-Band configuration, and in the present paper we discuss a first experiment to assess its first-order performance. It should be stressed that the RegCM system was not originally intended to be run in this global-like mode, so that this provides a very stringent test of its behavior.

The experiment discussed here consists of a $5 \mathrm{yr}$ simulation for the period 1998-2002 using ERAInterim reanalysis boundary conditions $(\mathrm{BC})$ at the northern and southern boundaries and observed seasurface temperatures (SST) at the lower boundary. This choice of $5 \mathrm{yr}$ was made in order to include a strong El Niño event (1998) and a La Niña event (2000) and is also justified by the maximum overlapping time between the ERA-interim needed as BC and the Climatic Research Unit (CRU; Mitchell et al.
2004) observed temperature dataset used to validate the model. Although this is not a long enough run to provide robust information on climate variability, it is sufficiently long to provide an assessment of systematic biases in the model climatology, particularly because it is referred to a specific hindcast period. A base analysis of this simulation is conducted, comparing the model results with observed precipitation, temperature and large-scale circulations, both for the entire model domain and for 5 common monsoon sub-regions: Sahel, eastern Africa, India, northern Australia and Central America (Fig. 1). An analysis of the model performance in reproducing first-order El Niño-Southern Oscillation (ENSO) patterns is also presented, as ENSO is a key phenomenon regulating tropical climate variability.

\section{DESCRIPTION OF REGT-BAND}

RegCM4 is an evolution of the previous version, RegCM3, described by Pal et al. (2007). The main model characteristics along with some test and sensitivity experiments over various domain specifications from the CORDEX program (Giorgi et al. 2009) are described in Giorgi et al. (2012). RegCM4 is a hydrostatic, sigma-p vertical coordinate model with multiple physics options. For the present experiment we use the following options described in Giorgi et al. (2012): modified CCM3 radiative transfer scheme (Kiehl et al. 1996), modified Holtslag et al. (1990) planetary boundary layer scheme, SUBEX resolvable

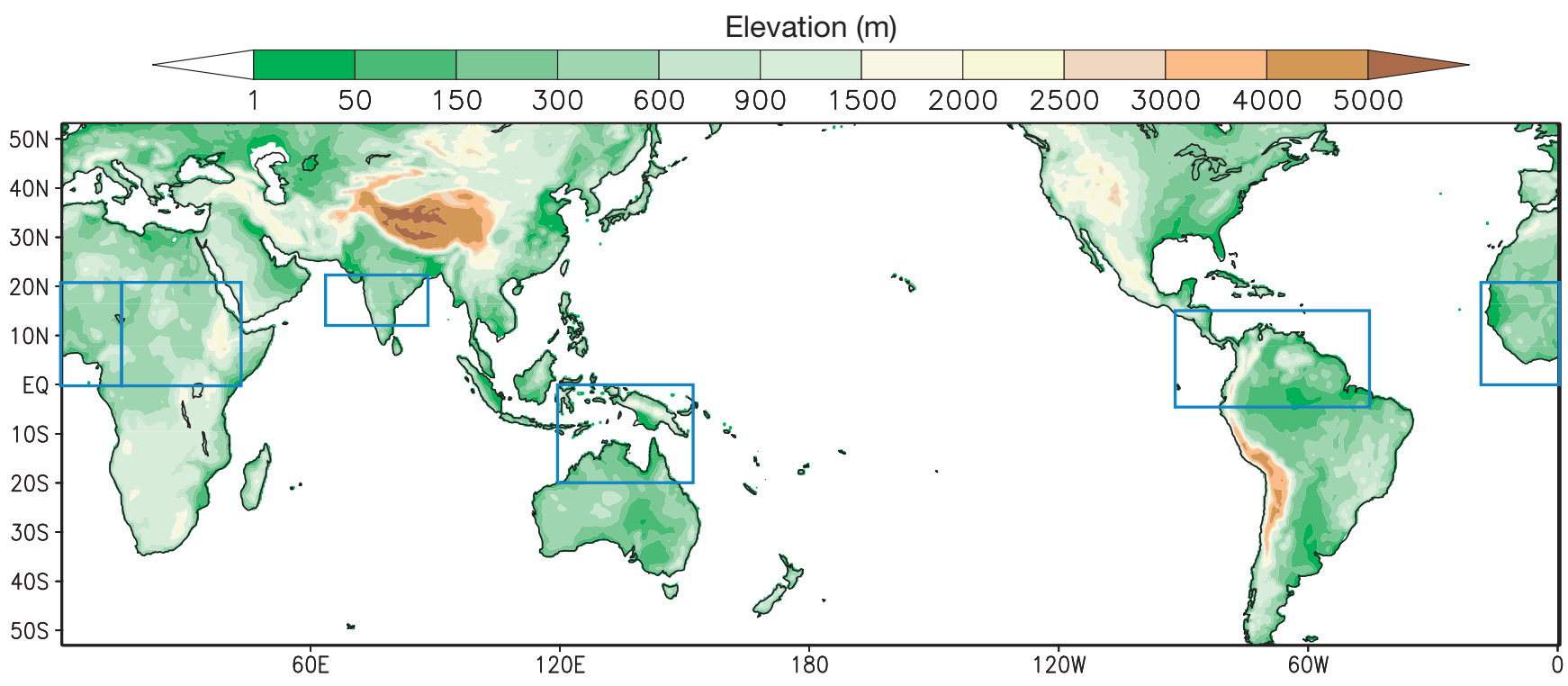

Fig. 1. Model domain and topography. Also shown are 5 monsoon regions selected for more detailed analysis: Sahel, East Africa, India, northern Australia and northern South America 
precipitation scheme (Pal et al. 2000), mixed cumulus convection configuration utilizing the scheme of Grell (1993) over land and that of Emanuel (1991) over oceans and the biosphere-atmosphere transfer scheme (BATS; Dickinson et al. 1993) land surface package. This choice of physics schemes was made after a series of preliminary test experiments not only in the RegT-Band configuration but also in limited area domains (Giorgi et al. 2012).

The tropical band configuration is implemented in a straightforward way. Using a Mercator projection horizontal grid, the grid interval is chosen as:

$$
D x=2 \pi R / N
$$

where $R$ is the radius of the Earth and $N$ is the number of grid points in an east-west direction. With this choice of $D x$, the end points at the eastern and western boundaries exactly overlap; therefore, if periodic lateral $\mathrm{BCs}$ are used in an east-west direction, a continuous field is obtained for a tropical band encompassing the entire Earth's circumference. For our experiment we chose $N=1024$ so that the model can be run in multi-tasking mode with good scalability up to 256 processors (1024/4). This yields a grid interval of about $39 \mathrm{~km}$. In a north-south direction the domain extends from about $50^{\circ} \mathrm{S}$ to $50^{\circ} \mathrm{N}$, and a standard exponential relaxation procedure (Giorgi et al. 1993) is used in the southern and northern boundaries over a buffer zone with a 12 grid point width. Therefore, the model uses forcing lateral BC only in the northern and southern boundaries of the domain, with no external forcing in an east-west direction (periodic conditions at the overlap end points). Finally, the model utilizes 18 vertical sigma levels and a top at $50 \mathrm{hPa}$, as in its standard configuration. Fig. 1 shows the model domain and topography along with some sub-regions selected for more detailed regional analysis.

Forcing conditions at the northern and southern boundaries are obtained from the ERA-Interim reanalysis of observations (Uppala et al. 2008), and SSTs at the lower boundary are taken from Reynolds et al. (2002). The simulation period starts on 1 January 1998 and ends on 31 December 2002. Observed data used for model validation include the Tropical Rainfall Measuring Mission $\left(\mathrm{TRMM}, 0.25^{\circ} \times 0.25^{\circ}\right.$ resolution daily precipitation product; Kummerow et al. 2001, Huffman et al. 2007), the Global Precipitation Climatology Project daily precipitation dataset (GPCP, $1^{\circ} \times 1^{\circ}$ resolution; Huffman et al. 2001), the CRU 0.5 degree resolution land temperature and precipitation monthly data and the ERA-Interim atmospheric and surface fields.

\section{ANALYSIS OF MODEL SIMULATION}

\subsection{Mean climatology}

Figs. 2, 3 \& 4 first compare the ERA-Interim and RegT-Band simulated zonally averaged temperature, u-wind and vertical velocity (omega) cross sections (in pressure coordinates) in December-JanuaryFebruary (DJF) and June-July-August (JJA). Clearly the model reproduces the basic features of both mean temperature and circulation as found in the ERA-Interim reanalysis. The vertical and latitudinal temperature gradients are consistent across the 2 datasets, as is their seasonal variation. The model shows a mid-tropospheric cold bias core of up to $3-4^{\circ} \mathrm{C}$ and an upper tropospheric warm bias locally reaching several degrees. Concerning the zonal wind (Fig. 3), the model reproduces the main jet core structure in both seasons. Compared to ERA-Interim the westerly upper tropospheric jet cores in the winter season are displaced slightly poleward. The location of the low level summer easterly tropical jets is well reproduced by RegT-Band, although the intensity of these jets is somewhat greater than in the reanalysis. Similarly, the upper tropospheric equatorial easterly jet core is well placed, but it is stronger in the model than in ERA-Interim by up to several meters per second. The ascending and descending branches of the Hadley cell are well located by the model (Fig. 4), although the intensity of the vertical velocity between the equator and $10^{\circ} \mathrm{N}$ in DJF is overestimated. This is dynamically consistent with the overestimation of precipitation and westerly flow by the model (see below, Figs. 6 \& 9) over the Pacific Ocean in the same season at the same latitude. From Fig. 4 it is also seen that the ITCZ position is well reproduced in JJA in, but, in DJF, the model shows a slightly northern displacement of the convergence zone and underestimates the strength of the cell south of the equator. Despite the presence of the systematic biases discussed above, Figs. 2-4 show that the RegT-Band configuration captures the overall large-scale structure of the tropical troposphere.

Fig. 5 shows the zonal precipitation cross section for DJF and JJA, land only and land + ocean (full data and without the Indian Ocean, see below, this section) areas in RegT-Band, TRMM, GPCP, ERA-Interim and CRU (for the land-only figure). When both land and ocean areas are considered, in JJA, the model captures the magnitude and location of the Inter-Tropical Convergence Zone (ITCZ) at about $10^{\circ} \mathrm{N}$. The subequatorial secondary peak is slightly displaced to the south, while precipitation is overestimated between 
a) $\mathrm{RegCM}$

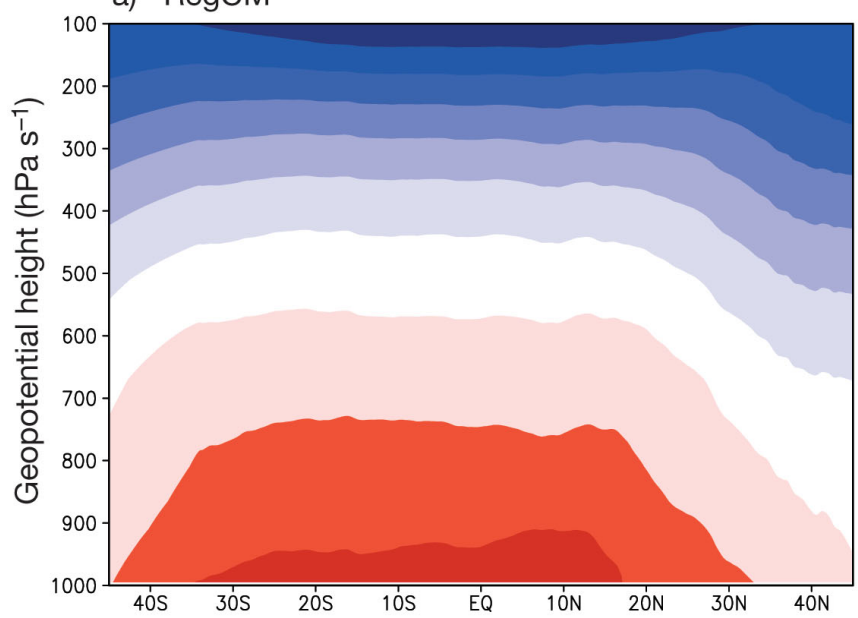

c) ERA-Interim

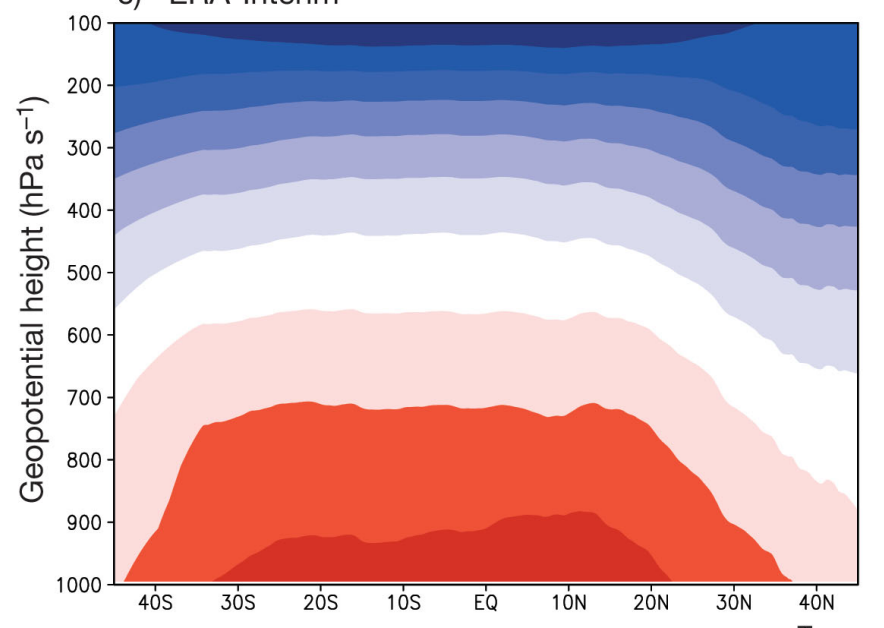

b) $\mathrm{RegCM}$

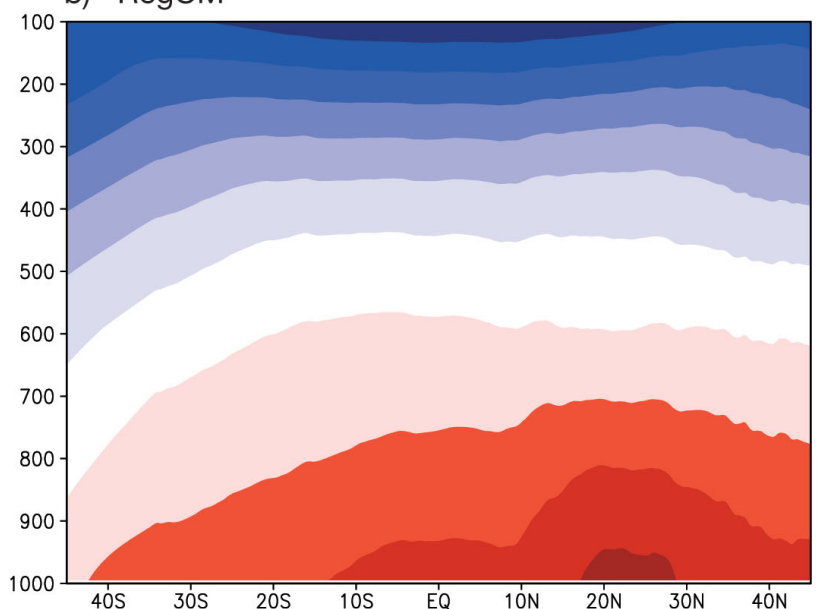

d) ERA-Interim

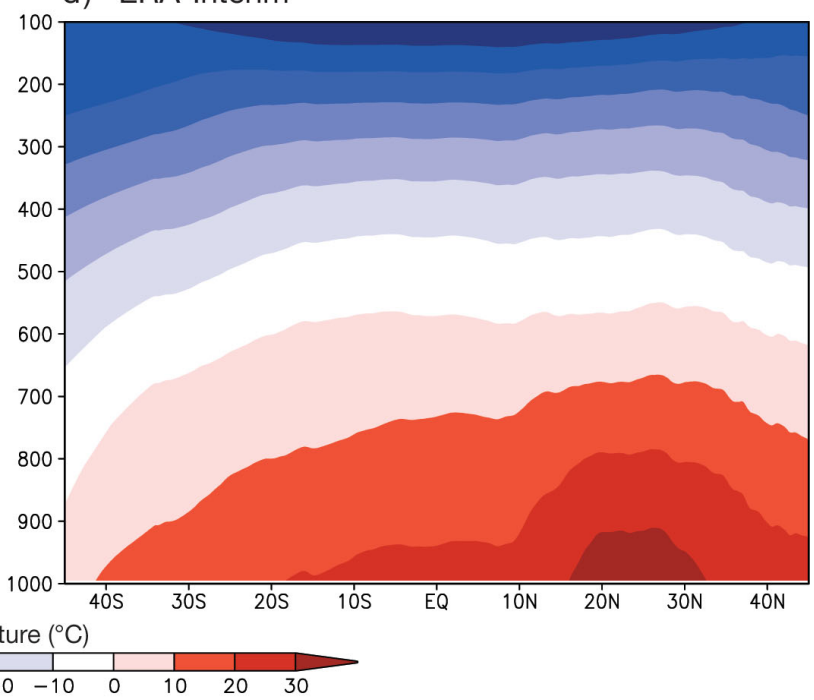

e) RegCM-ERA-Interim

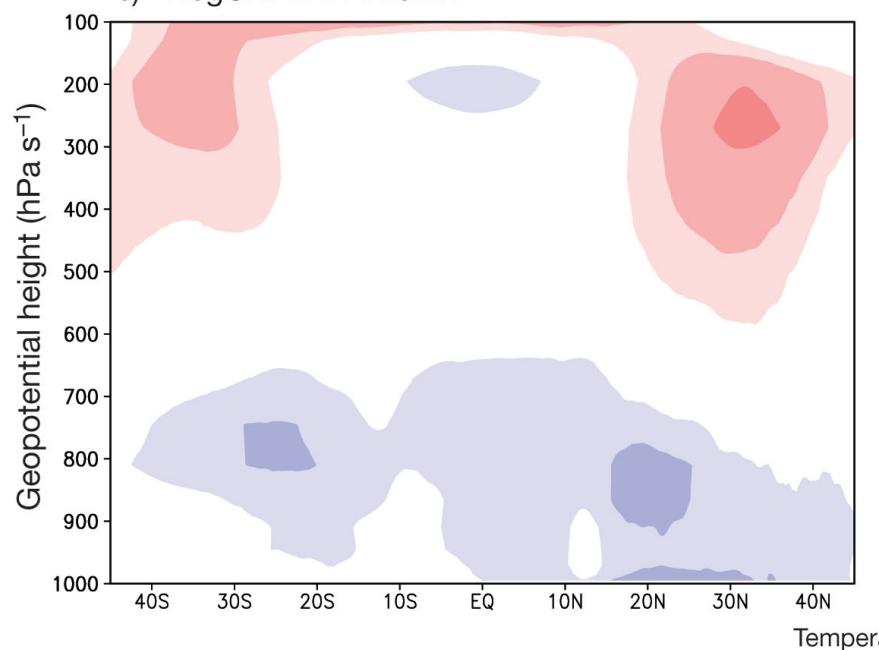

f) RegCM-ERA-Interim

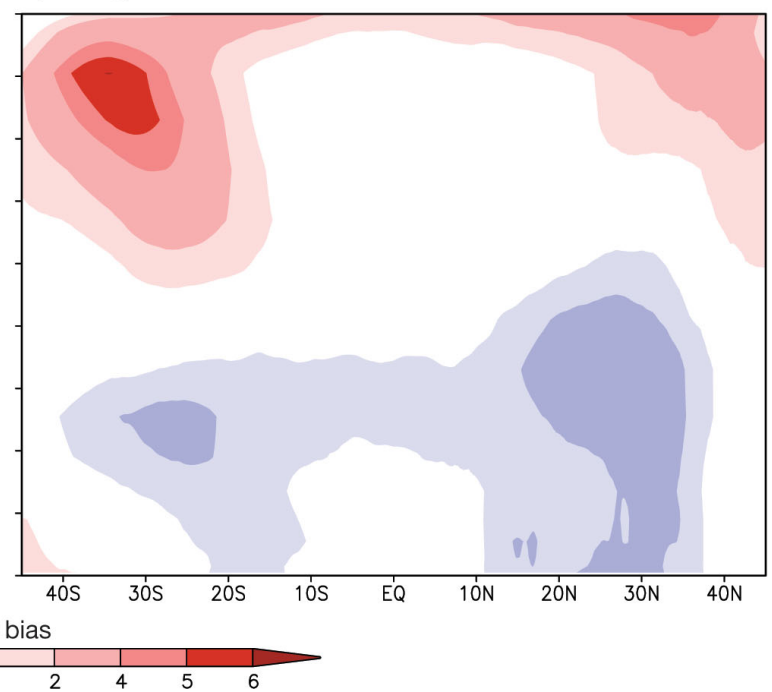

Fig. 2. Mean (1998-2002) zonal temperature cross section $\left({ }^{\circ} \mathrm{C}\right)$ for December-January-February (DJF; left panels) and JuneJuly-August (JJA; right panels) in RegT-Band $(\mathrm{a}, \mathrm{b})$ and ERA-Interim $(\mathrm{c}, \mathrm{d}) .(\mathrm{e}, \mathrm{f})$ Temperature bias for DJF and JJA, respectively 
a) $\mathrm{RegCM}$

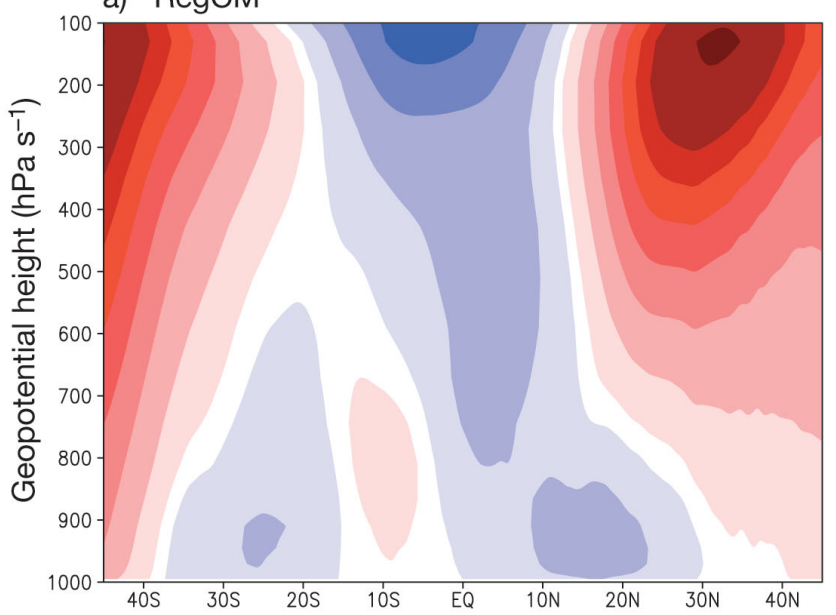

c) ERA-Interim

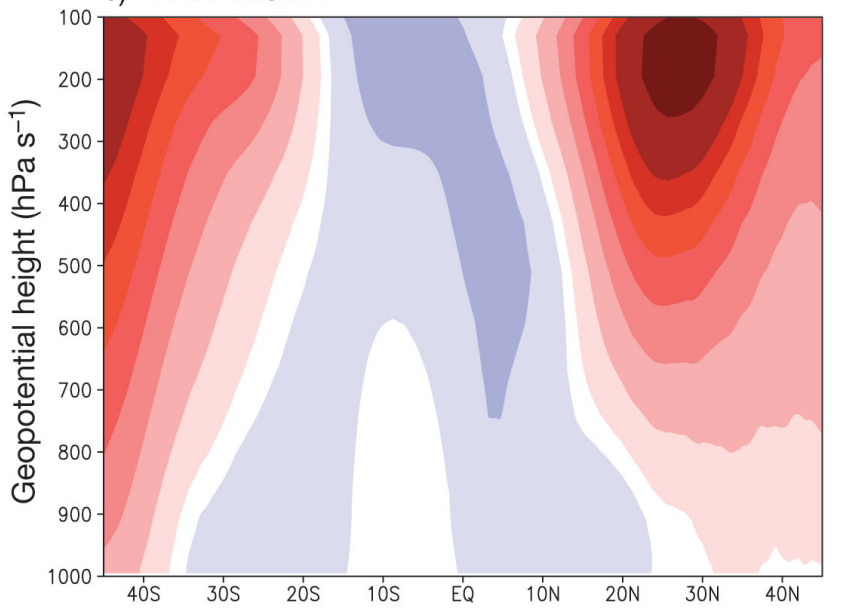

b) $\mathrm{RegCM}$

JJA

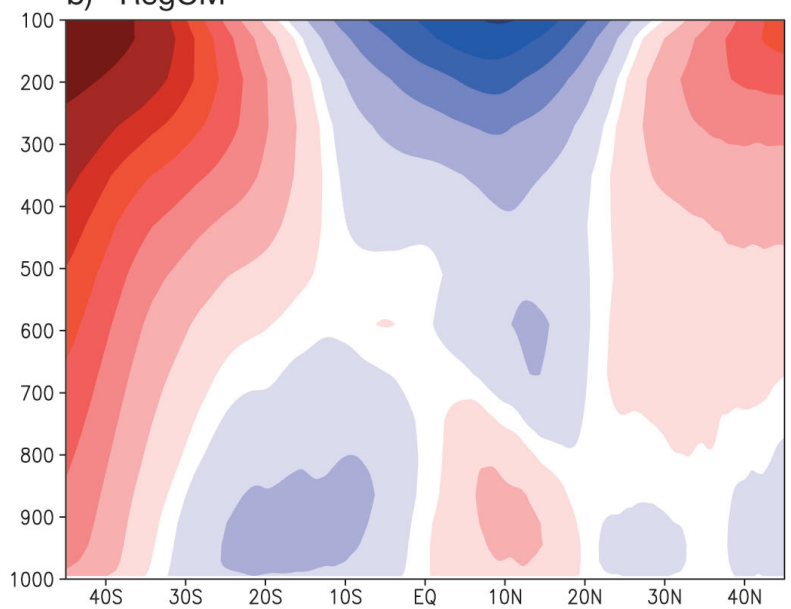

d) ERA-Interim

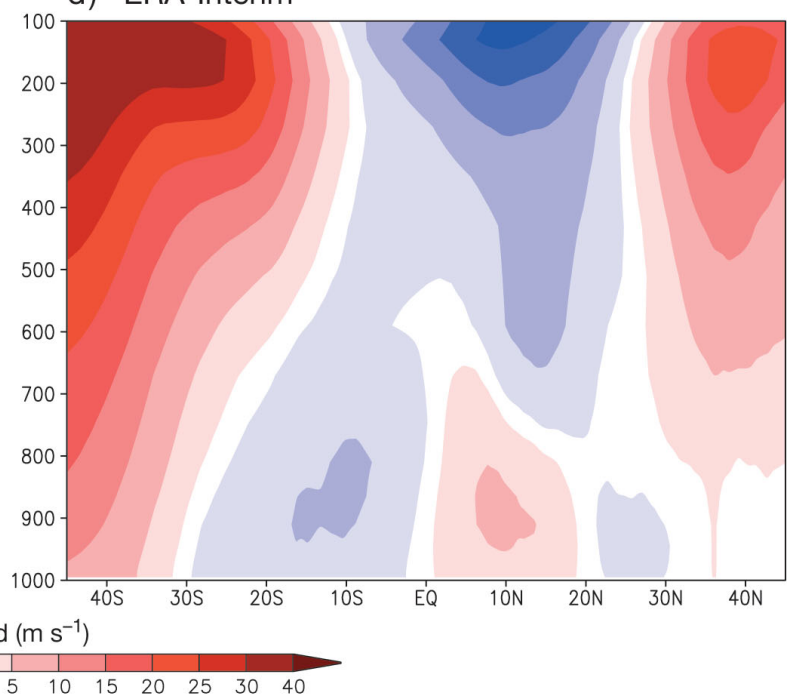

e) RegCM-ERA-Interim

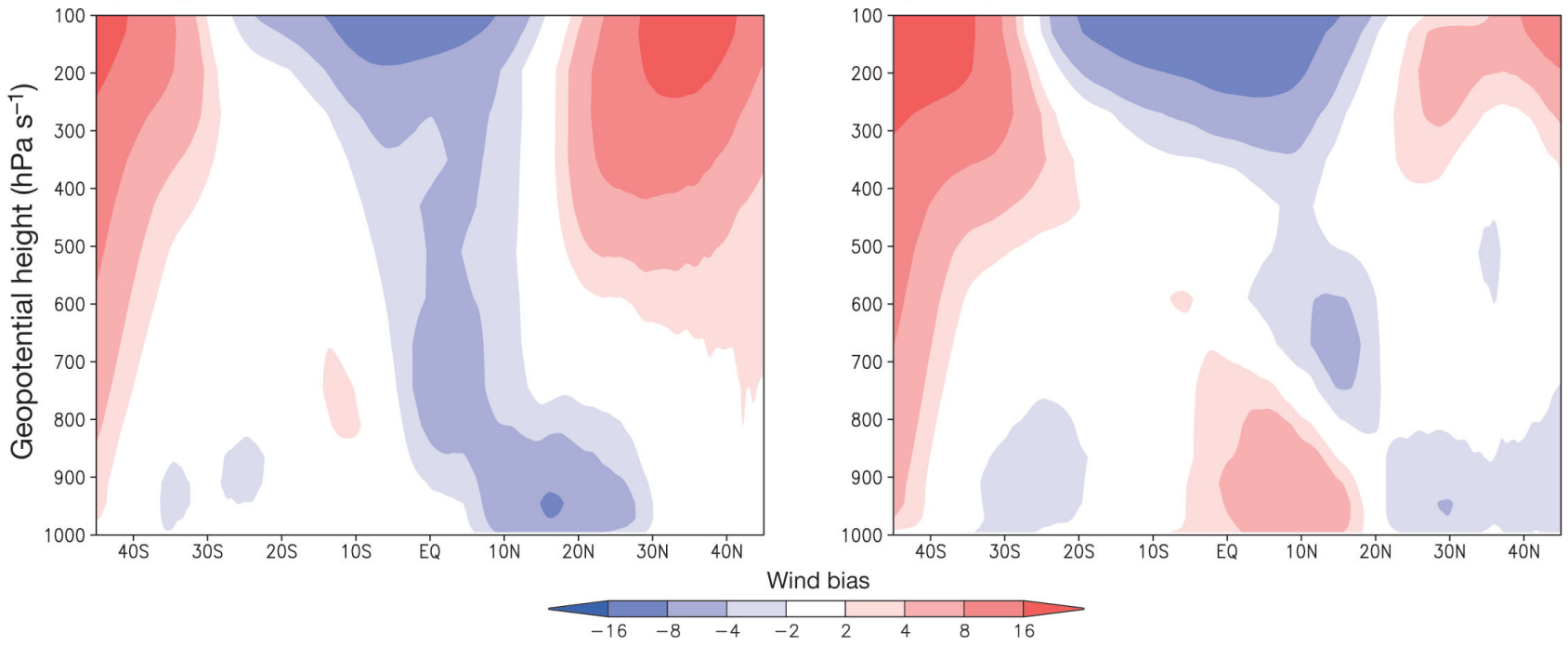

Fig. 3. Mean (1998-2002) zonal wind cross section $\left(\mathrm{m} \mathrm{s}^{-1}\right)$ for DJF (left panels) and JJA (right panels) in RegT-Band (a,b) and ERA-Interim $(c, d) .(e, f)$ Wind bias for DJF and JJA, respectively 

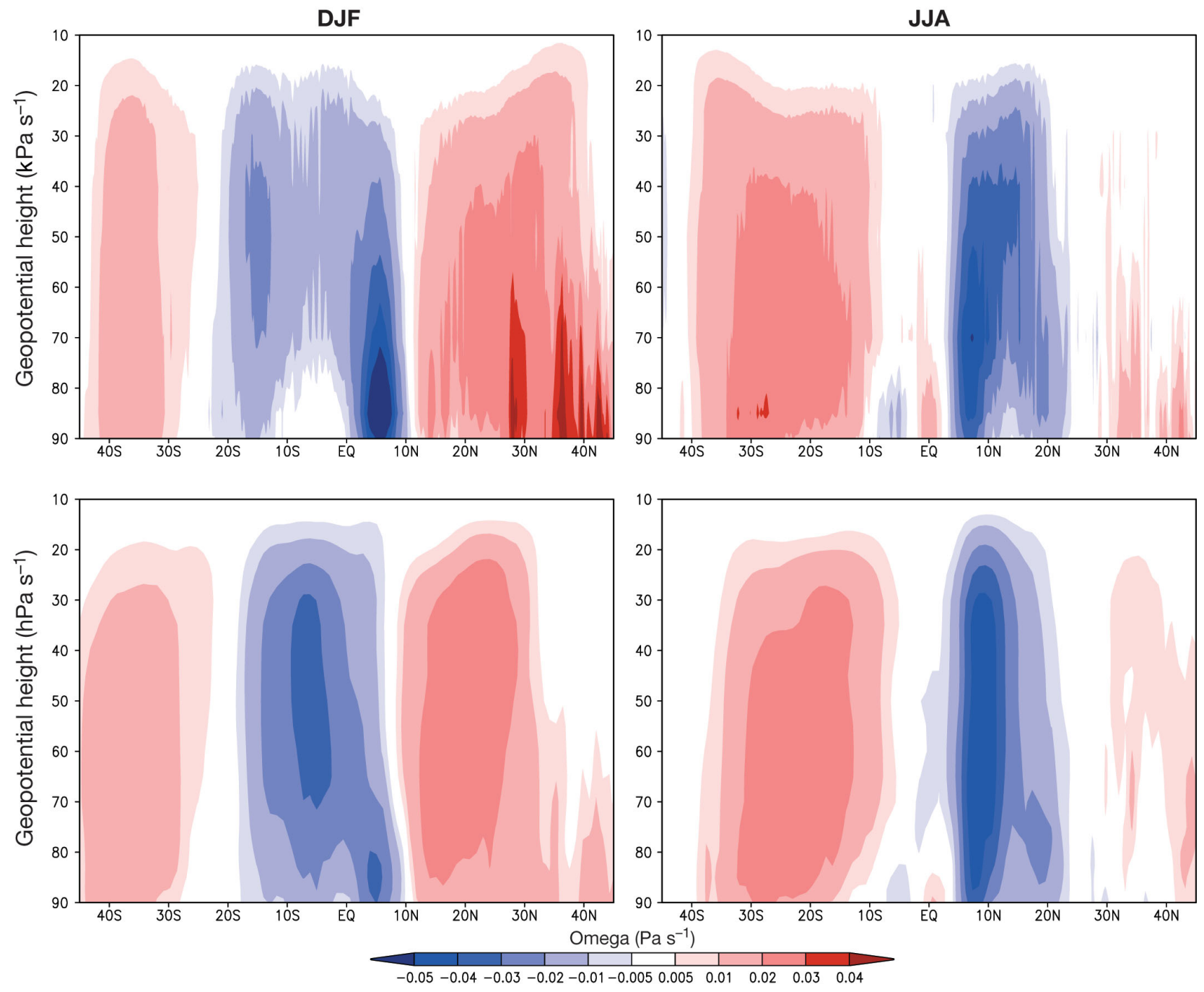

Fig. 4. Mean (1998-2002) zonal omega (dp/dt) cross section for DJF (left panels) and JJA (right panels) in RegT-Band (upper panels) and ERA-Interim (lower panels)

15 and $30^{\circ} \mathrm{N}$. Finally, precipitation is well simulated south of $25^{\circ} \mathrm{S}$ and north of $30^{\circ} \mathrm{N}$. In DJF the model performance deteriorates in the equatorial regions. In fact, the model displaces to the south and underestimates the sub-equatorial ITCZ primary maximum and overestimates the north-equatorial one. Comparison with the land-only precipitation cross sections (Fig. 5a,b) suggests that this problem is mostly related to ocean precipitation, as land precipitation is by and large well reproduced in both seasons.

To better understand this model bias, Fig. 6 compares TRMM, GPCP and RegT-Band spatial distribution of mean precipitation and bias for DJF and JJA. The main features of the spatial distribution of tropical precipitation are reproduced by the model. The ITCZ is well placed over both the Pacific and Atlantic Oceans in JJA, while a slight displacement to the south over the western equatorial Pacific is found in
DJF. The mid-latitude storm tracks off the major continental areas are also captured, as are the precipitation patterns over the continental areas (which will be examined in greater detail in Section 3.2). Among the main model deficiencies, however, we find an overestimate of precipitation over the warm pool and the western Pacific regions and, especially, areas of the Indian Ocean, where the precipitation patterns are somewhat misplaced compared to observations.

It therefore appears from Fig. 6 that an important contribution to the model-observation discrepancies in both the DJF and JJA zonal precipitation patterns illustrated in Fig. 5 are contributed by the Indian Ocean. In order to assess this contribution, Panels e and $f$ of Fig. 5 compare simulated and observed zonal precipitation when the Indian Ocean region is removed (area between 50 and $110^{\circ} \mathrm{W}$ ). The removal of the Indian Ocean leads to improved agreement 
DJF
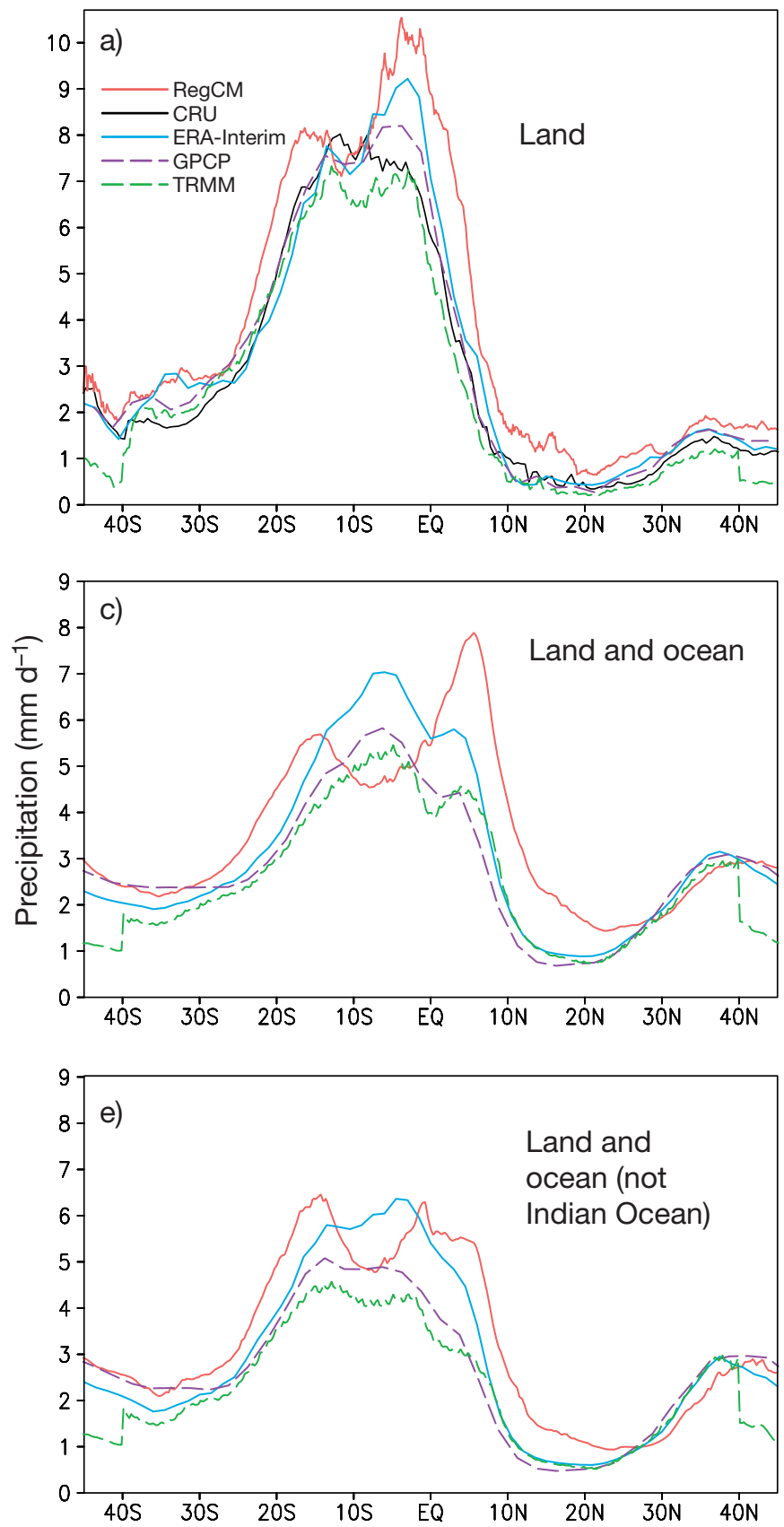

JJA
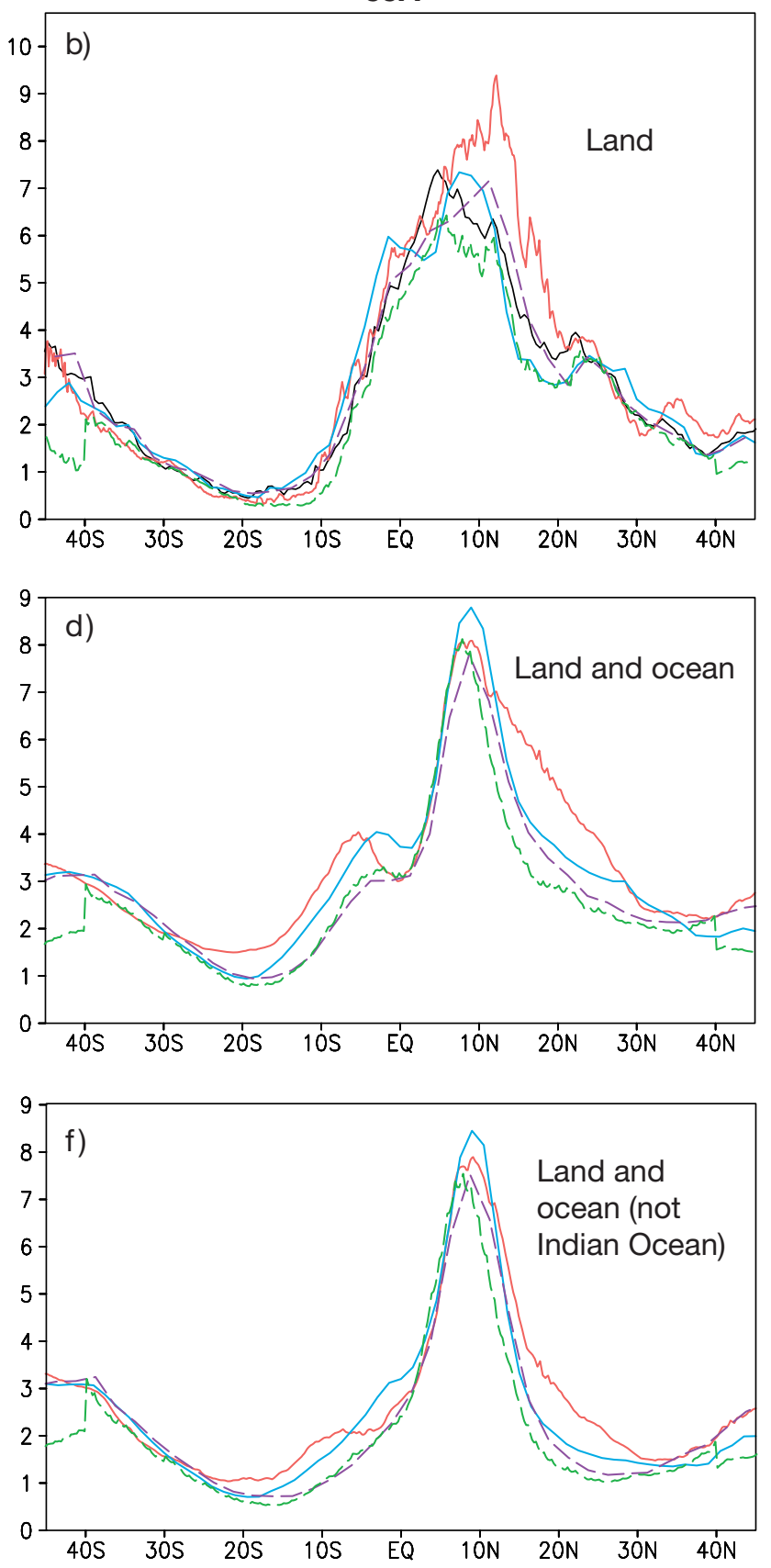

Fig. 5. Zonally averaged precipitation (1998-2002) for DJF (left panels) and JJA (right panels) for land only areas (a,b), land + ocean areas $(c, d)$ and land + ocean areas with the Indian ocean removed $(e, f)$

with observations in both seasons. In JJA the excess simulated precipitation between $15^{\circ}$ and $30^{\circ} \mathrm{N}$ is substantially reduced (although not entirely removed), while in DJF the precipitation double peak appears more in line with observations, although still overestimated. It thus appears that the use of the Emanuel scheme over the Indian Ocean does not provide a good simulation of precipitation there, and different convection schemes, along with the use of interactive oceans, might provide a better representation of Indian Ocean precipitation (e.g. Ratnam et al. 2009, Mariotti pers. comm.). Indeed, the study by Davis et al. (2009) indicates that precipitation over the Indian Ocean is sensitive to the choice of convective parameterization. More testing is require to improve this aspect of the model. 

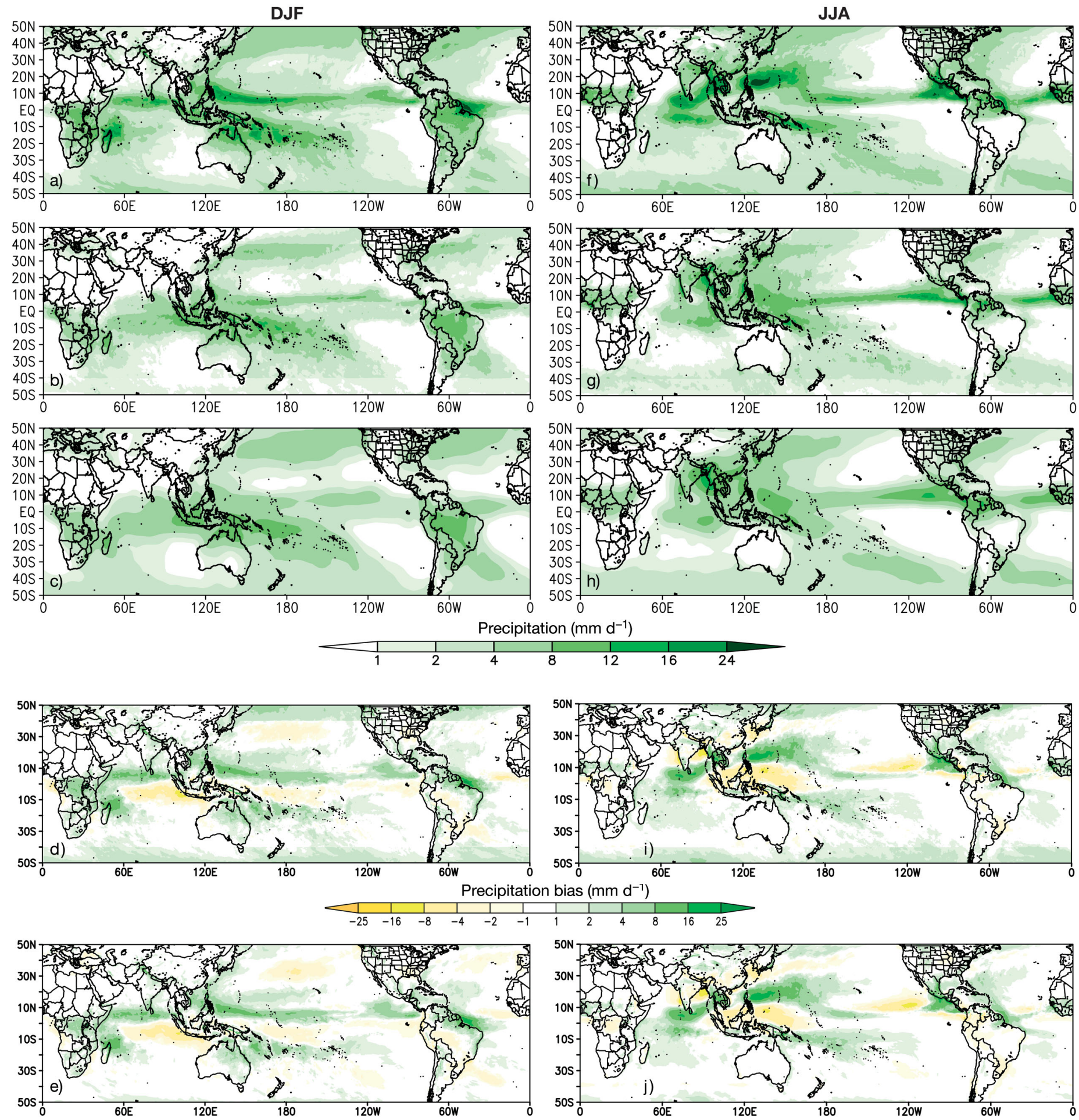

Precipitation bias $\left(\mathrm{mm} \mathrm{d}^{-1}\right)$

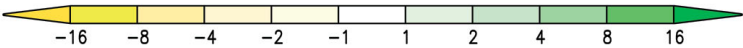

Fig. 6. Mean precipitation (1998-2002) for DJF and JJA in RegT-band (a,f), TRMM (b,g) and GPCP (c,h). Precipitation bias for DJF and JJA compared to TRMM $(\mathrm{d}, \mathrm{i})$ and GPCP $(\mathrm{e}, \mathrm{j})$ 
Fig. 7 compares the near-surface air temperature over tropical land regions in RegT-Band, ERA-Interim and CRU observations. For DJF the model shows excellent agreement with observations south of $30^{\circ} \mathrm{S}$ and north of $10^{\circ} \mathrm{N}$, while it underestimates land surface temperature by a few degrees between $30^{\circ} \mathrm{S}$ and $10^{\circ} \mathrm{N}$ compared to CRU. Similar behavior is found for JJA, with good agreement south of $10^{\circ} \mathrm{S}$ and an underestimate in the other regions. The ERAInterim reanalysis produces near-surface temperatures that are generally intermediate between RegTBand and CRU.

Fig. 8 shows the spatial distribution of the temperature biases. Clearly, the model tends to be too cold by a few degrees in most land areas of the

Temperature

DJF

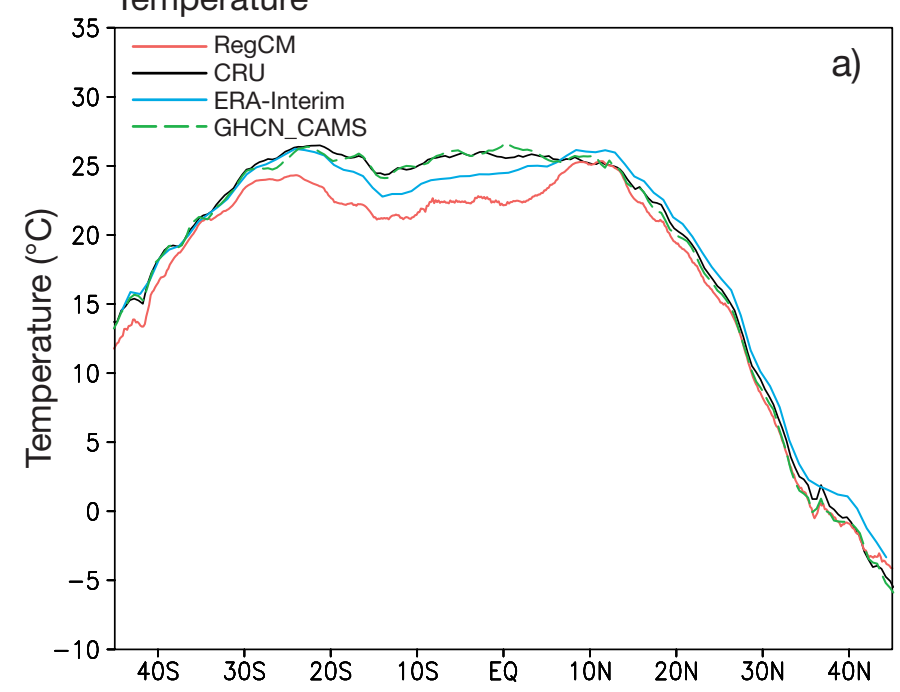

Tmax/Tmin

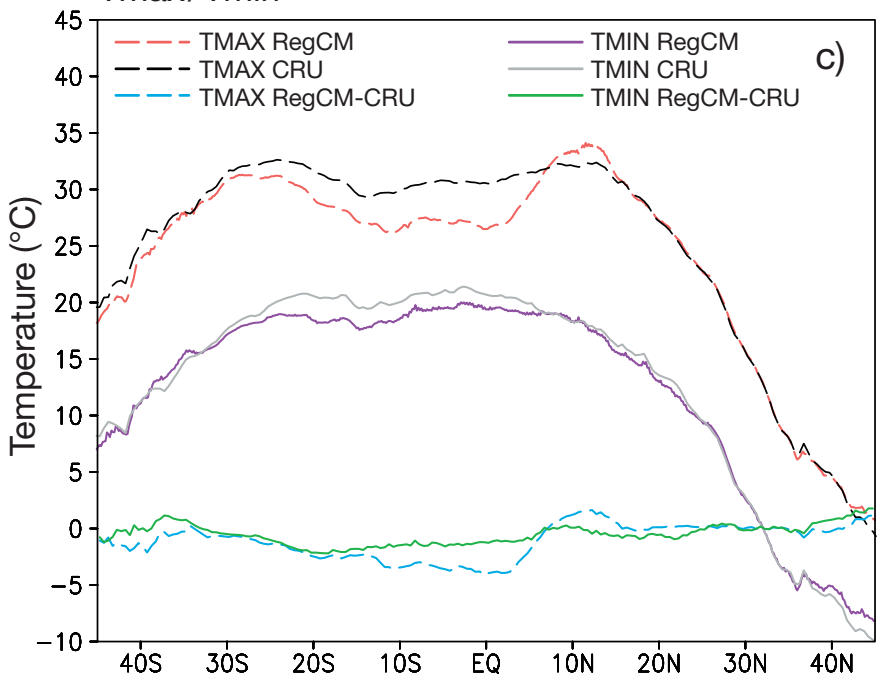

tropics in both seasons. To investigate the reasons for this systematic bias, a comparison of observed and simulated average daily maximum and minimum temperatures is also reported in Panels $\mathrm{c}$ and $\mathrm{d}$ of Fig. 7. It is clear from this figure that the greatest contribution to the cold temperature bias is from an underestimate of daily maximum temperature. This can, in turn, be traced to the diurnal cycle of precipitation. In the model, precipitation peaks mid-day, between 12:00 and 15:00 h, however, over many tropical regions the peak precipitation occurs in the evening (Biasutti et al. 2003, Diro et al. 2012, this Special). As a result the model has excessive cloud shading and evaporative cooling at mid-day, which tends to produce excessively
JJA
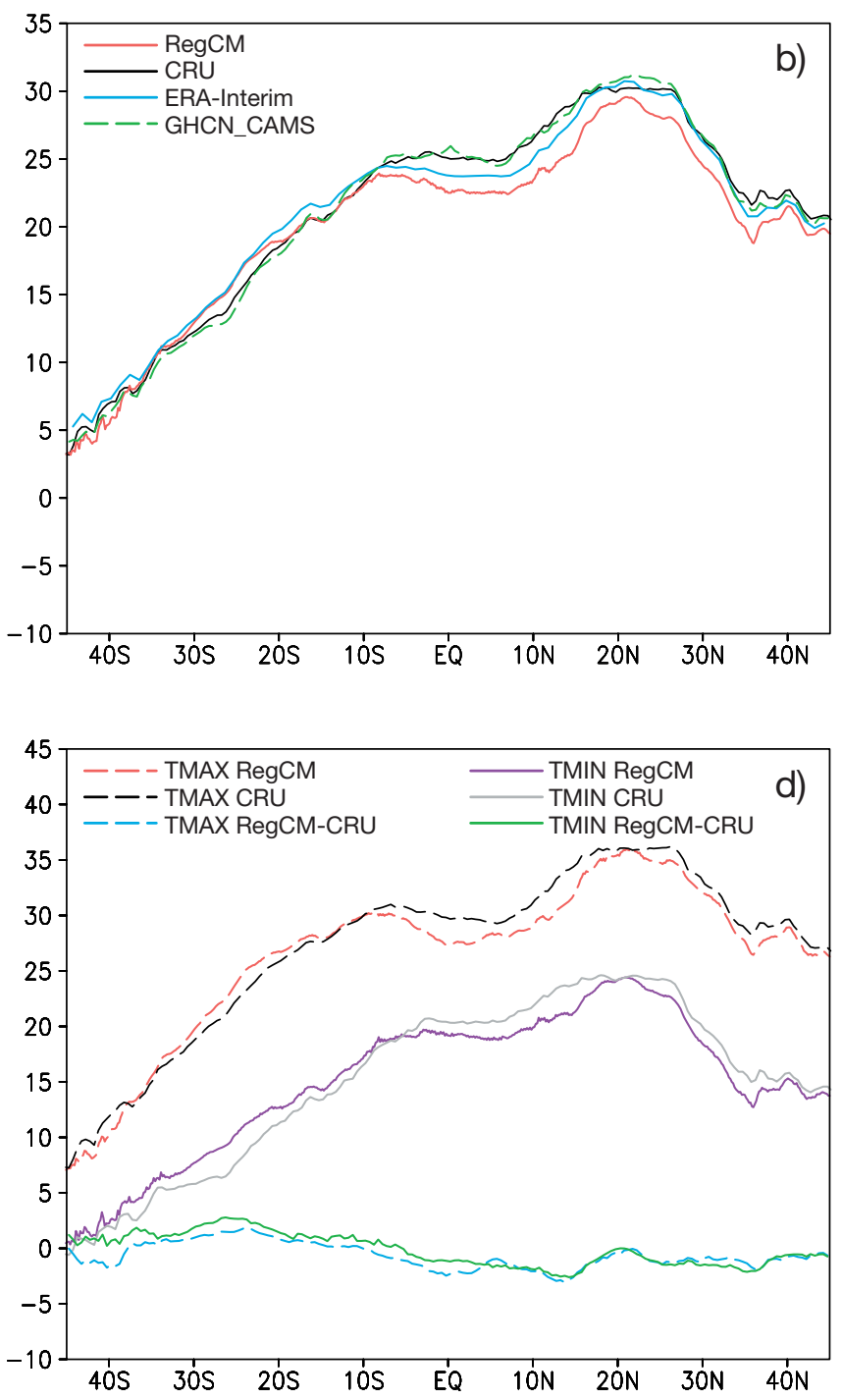

Fig. 7. Zonally averaged surface air temperature (land only, 1998-2002) in (a) DJF and (b) JJA. Zonally averaged surface maximum and minimum temperature and their differences compared to CRU (land only, 1998-2002) in (c) DJF and (d) JJA 

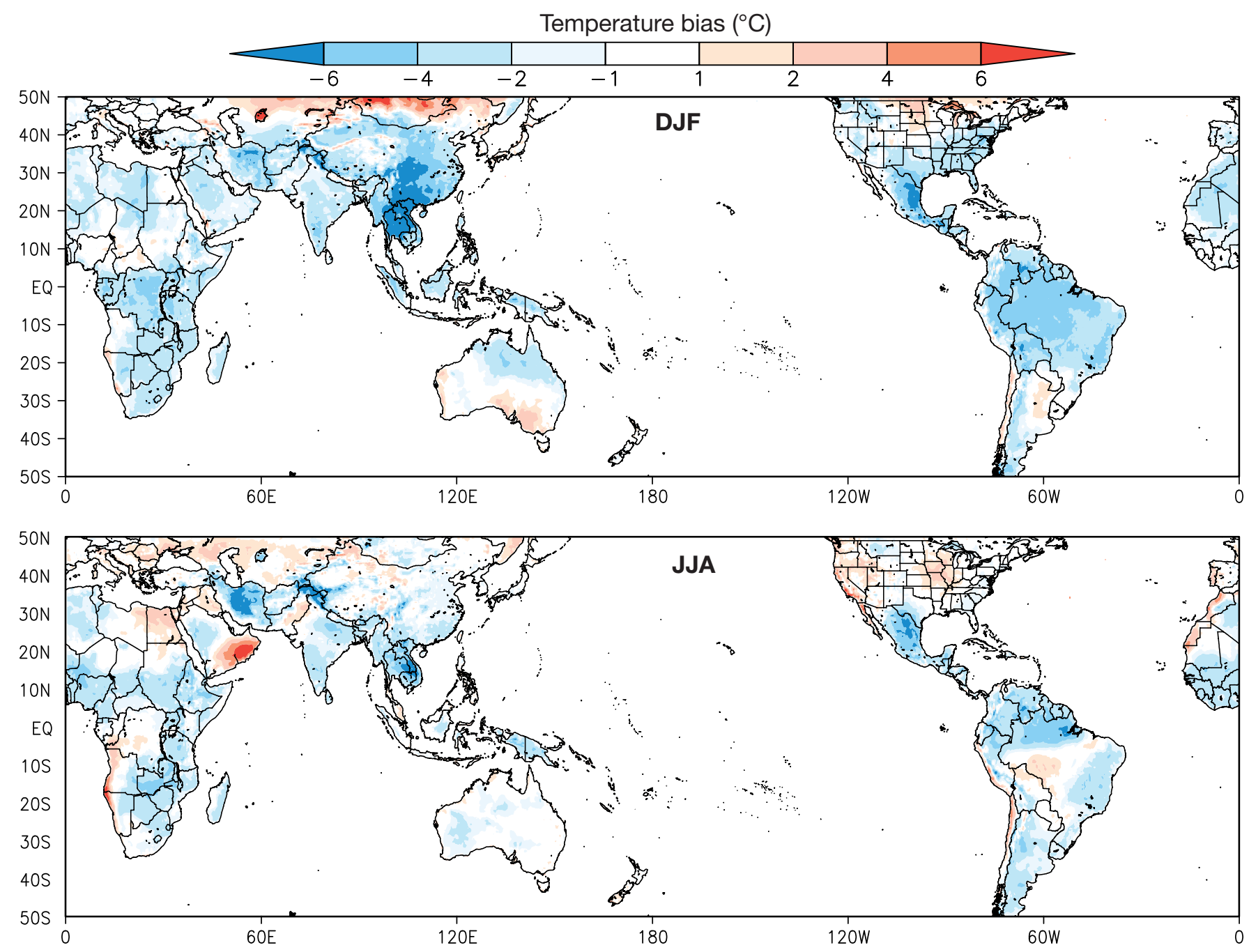

Fig. 8. Mean temperature bias (1998-2002) in RegCM-CRU for DJF (upper panel) and JJA (lower panel)

low maximum daytime temperatures. This is a common problem in climate models (Yang \& Slingo 2001, Collier \& Bowman 2004, Dai \& Trenberth 2004) and is related to the behavior of most convective schemes which strongly respond to local production of buoyant energy.

The tendency of RegCM to exhibit a cold bias over equatorial and tropical land regions has been noted in previous model applications (Giorgi et al. 2004, 2012). Other possible contributions to this bias may be related to excessive vertical transport in the Holtslag Planetary Boundary layer scheme or to excessive evapotranspiration produced by the BATS land surface scheme (Giorgi et al. 2012). It has also recently been found that the BATS surface albedos are generally larger than estimates from MODIS satellite observations (T. A. O'Brien pers. comm.), and this might also contribute to the model cold bias.
We also note that ERA-Interim generally shows lower temperatures than CRU and that, in tropical regions, the paucity of observation station data, particularly in remote areas, might yield significant uncertainties in the CRU dataset.

Finally, Fig. 9 compares $925 \mathrm{hPa}$ zonal wind in RegT-Band and ERA-Interim. Clearly the model reproduces the basic structure and seasonal migration of the surface easterlies, as well as some detailed regional patterns associated with the continental outlines. In JJA it is also evident that the Indian monsoon regime is well reproduce (westerly wind) compared to the reanalysis. Differences compared to ERA-Interim can, however, be found, for example over the northwestern equatorial Pacific, where the easterlies are stronger in the model than in ERAInterim, mainly for DJF. The same deficiency is also evident from Fig. 3. 

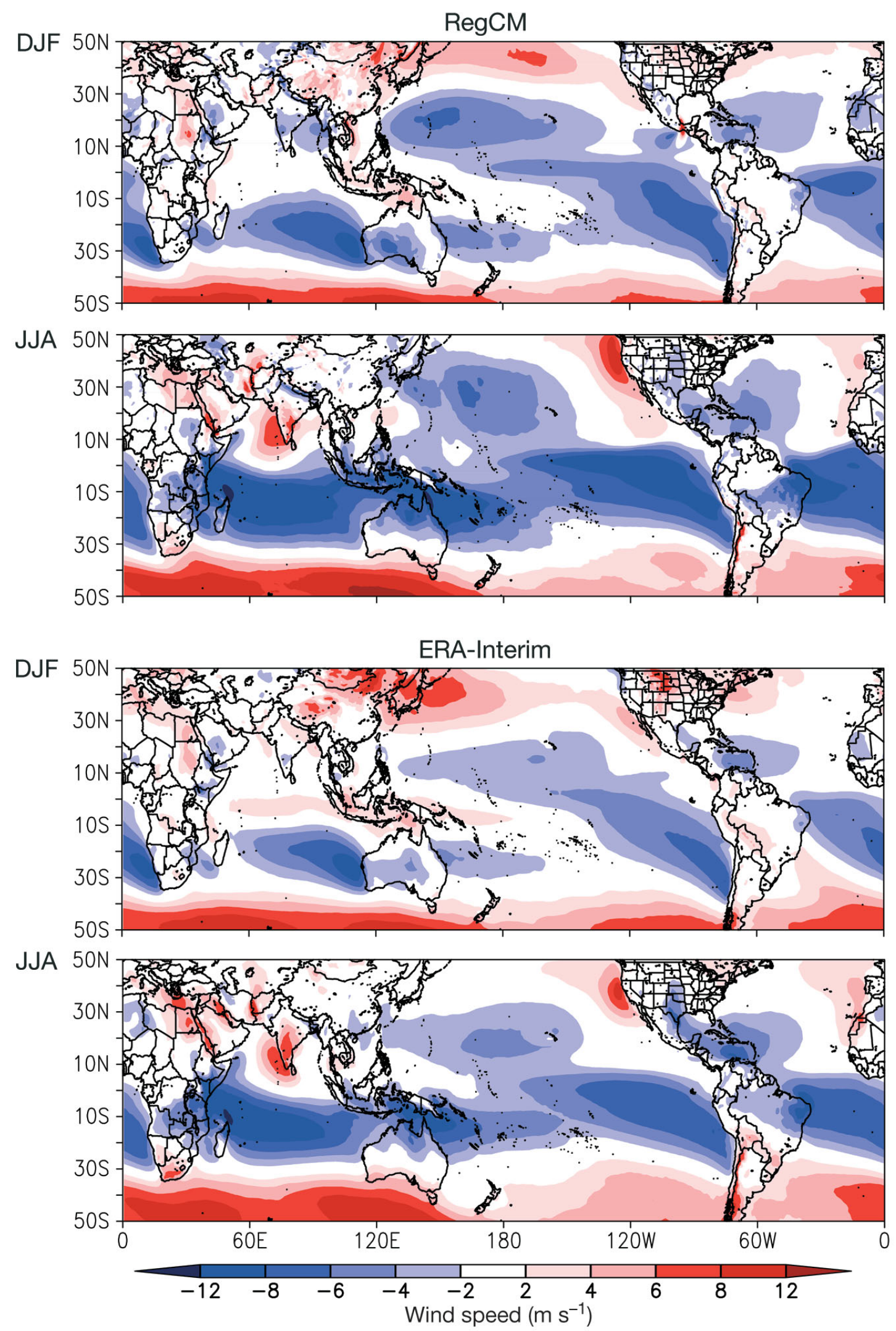

Fig. 9. Mean zonal component of the wind at $925 \mathrm{hPa}$ (1998-2002) in DJF and JJA according to RegT-Band (upper panels) and ERA-Interim (lower panels) 
As a summary assessment of the analyses in this section, we can conclude that, although some systematic model biases are found, the RegT-band configuration is able to simulate the basic circulation, temperature and precipitation patterns of the tropical atmosphere.

\subsection{Regional monsoon precipitation patterns}

In this section we turn our attention to the 5 monsoon sub-regions shown in Fig. 1 to assess whether the model can reproduce the seasonal and intraseasonal evolution of these regional monsoon systems.
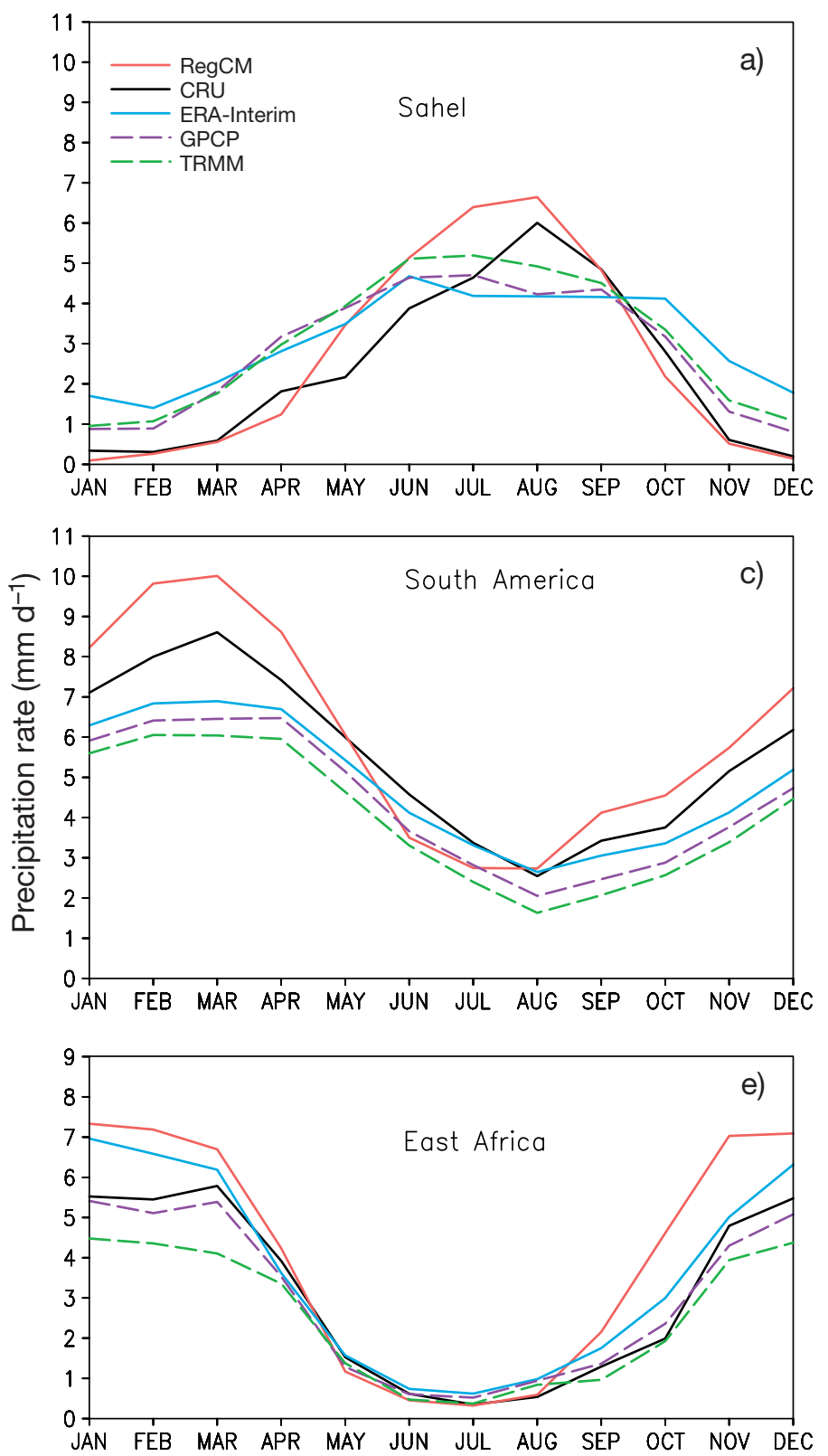

Towards this goal, Fig. 10 first shows the seasonal evolution of the regional average monthly precipitation (land only) in the RegT-Band, CRU, TRMM, GPCP and ERA-Interim datasets for the 5 regions, while Fig. 11 presents the corresponding Hovmoller diagrams based on daily precipitation (thus not for the monthly CRU data). The latter are zonal cross sections of daily precipitation which illustrate the intraseasonal evolution of the monsoon.

Over the Sahel region (Fig. 10) we first note a substantial discrepancy between the CRU observations, which are only station-based, and the TRMM and GPCP observations, which are mostly based on satellite products. In particular, the CRU precipitation is
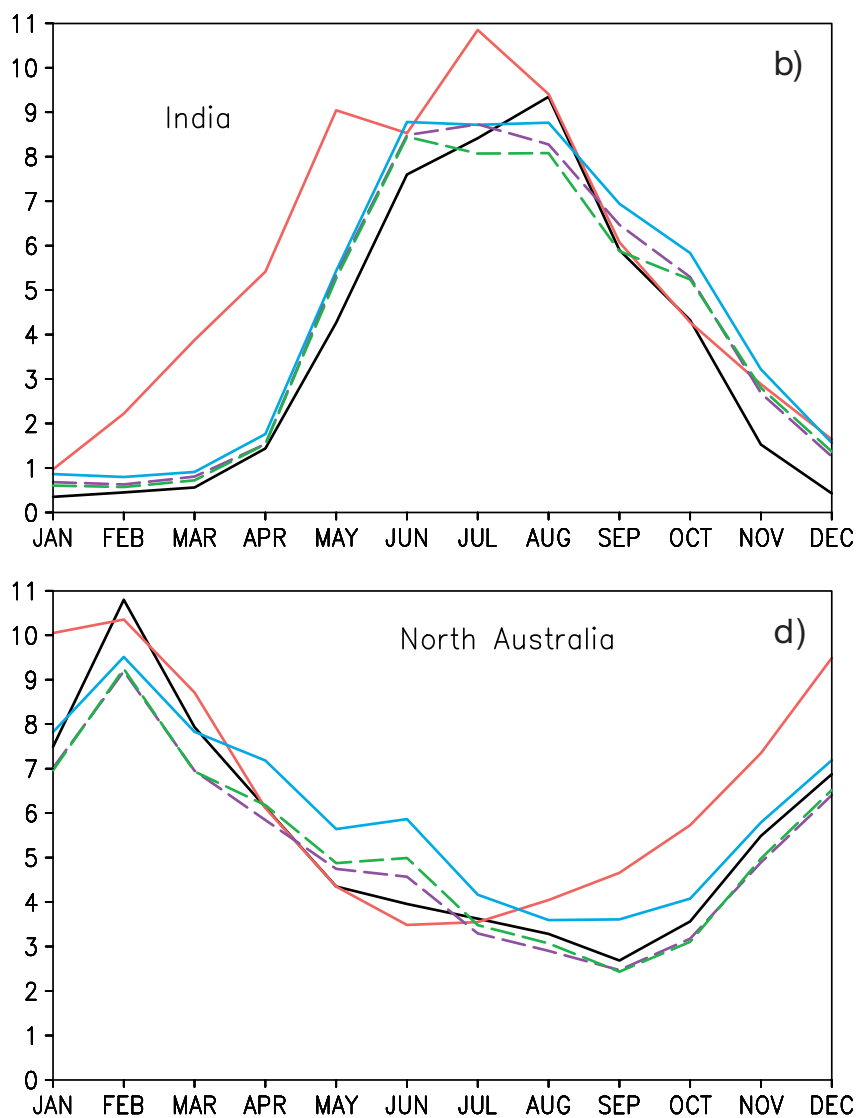

Fig. 10. Mean annual precipitation cycle over the 5 regions of Fig. 1 (land only, 1998-2002): (a) Sahel, (b) India, (c) northern South America, (d) northern Australia and (e) East Africa 

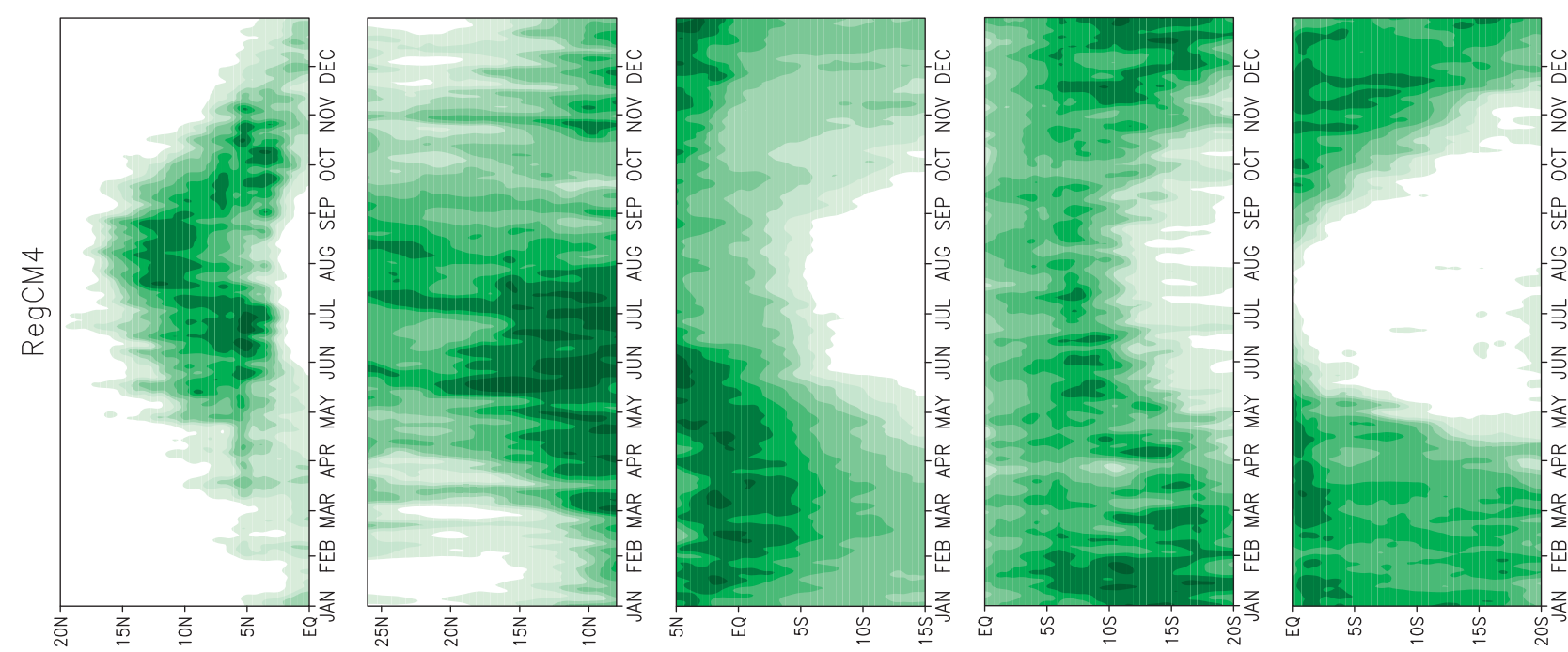

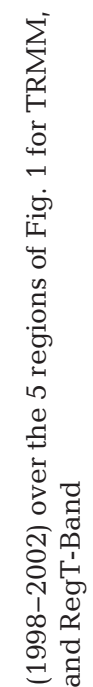
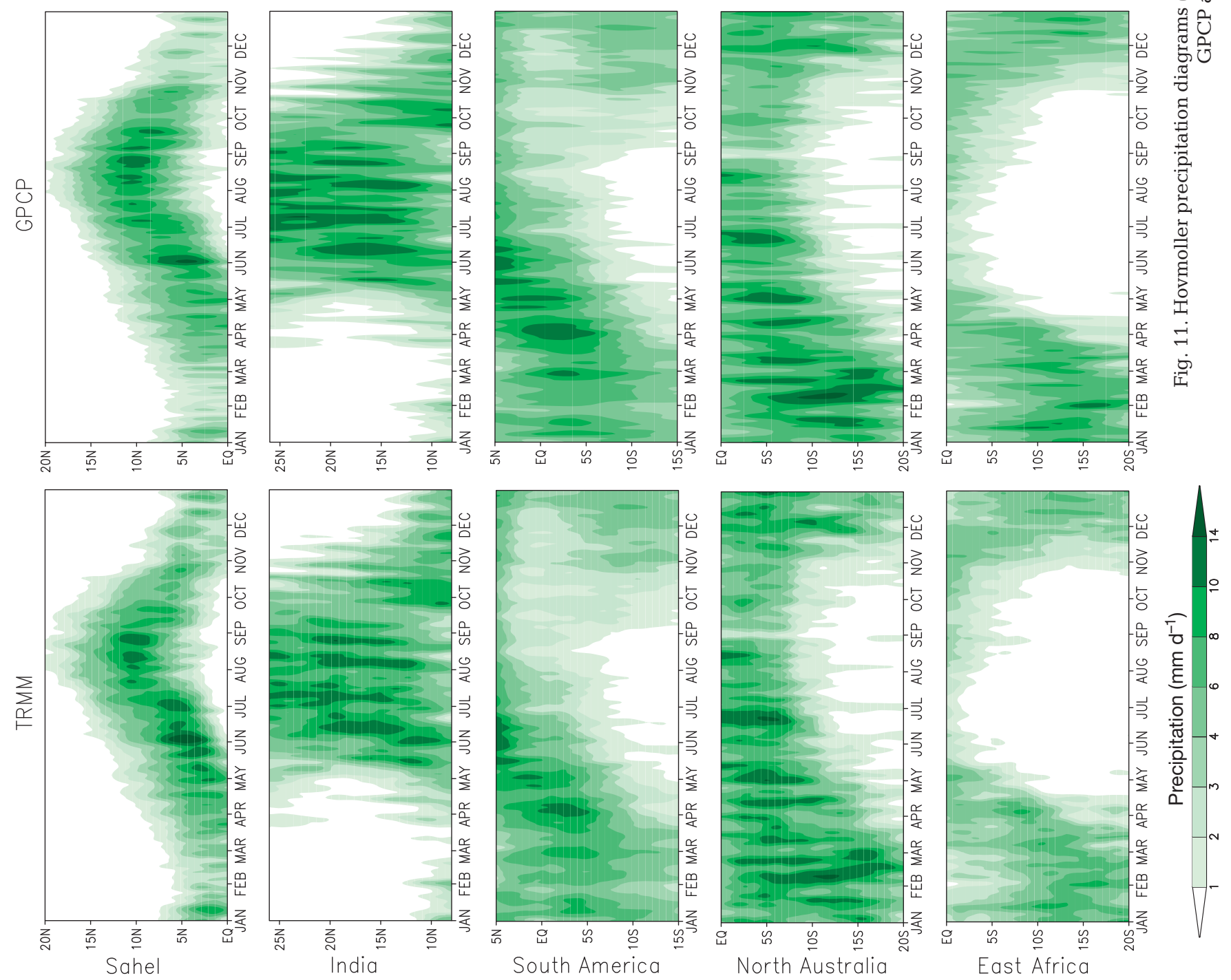
substantially lower in the onset and recession phases of the monsoon and exhibits a peak during the mature phase, which is misplaced compared to the other observation datasets. The RegT-Band precipitation is close to CRU in the early onset and recession phases of the monsoon (and thus it is underestimated compared to the other datasets), while it is greater than observed in the mature monsoon phase. The East African monsoon precipitation shows better agreement between the CRU and satellite-based observations. The model slightly overestimates the precipitation intensity in the central part of the rainy season, and it also anticipates the monsoon onset during the month of September.

Better agreement across the 3 observation datasets is found over continental India, with a peak monsoon phase in JJA. Over this region the model shows a clear overestimation during the pre- and early monsoon phases (February to May) and better agreement for the rest of the monsoon cycle (except for an overestimate in July). A problem of early monsoon onset also appears over the northern Australia region, where the observed monsoon rain peaks in February and is at a minimum in September. The model reproduces the February peak; however, it displaces the minimum in June because of precipitation overestimation between August and January. Finally, over the northern South America region the model reproduces the observed annual cycle of precipitation but overestimates the precipitation amounts, particularly compared with the satellite-based datasets, which show substantially lower precipitation than CRU. We finally note that the ERA-Interim precipitation shows good agreement overall, in particular with the TRMM and GPCP data over all regions, illustrating the improved quality of this reanalysis product over tropical regions (Uppala et al. 2008).

The regional Hovmoller diagrams in Fig. 11 are consistent with the monthly seasonal average results, but show substantial intraseasonal structure. Over the Sahel, the observed precipitation band shows 2 sudden northward jumps, 1 in early June and 1 in midJuly. Both jumps are reproduced and well placed by the model, although the intensity of precipitation is overestimated. Conversely, we observe an underestimate in the early and late monsoon phases, essentially between November and March. In East Africa the model is able to represent the monsoon onset and decay, but it overestimates the precipitation intensity in the equatorial areas.

Over India, the monsoon rain band quickly moves northward from about $10^{\circ} \mathrm{N}$ in May to $20-25^{\circ} \mathrm{N}$ in July, where it resides until mid-October when it starts moving south during the recession phase. The RegT-Band clearly shows an overestimate of precipitation between March and August at low latitudes, south of $15^{\circ} \mathrm{N}$, where the monsoon front appears to stagnate compared to observations. The simulated monsoon rain band does reach $20-25^{\circ} \mathrm{N}$ during the mature phase, and the monsoon recession is more in line with the observation datasets.

In the northern South America region the model reproduces the seasonal migration of the monsoon rain band; however, it overestimates precipitation in the equatorial regions during the mature monsoon phase (January through March). Finally, the northern Australia monsoon migrates from about $5^{\circ} \mathrm{S}$ in the austral winter months (July through October) to about $15^{\circ} \mathrm{S}$ in the mature phase (January-March). The RegT-Band reproduces this annual cycle, but displaces to the south (compared to observations) the monsoon front in the onset phase (September through November).

Overall, the results presented in this section indicate that the RegT-Band captures the basic evolution of the monsoon systems over different regions; however, it results in deficiencies compared to observations. In particular we find an early and overestimated onset of monsoon precipitation over the Indian and northern Australia monsoon regions. These may be associated with convection as well as surface process representations, and more testing is required to assess which model options and parameters can improve this problem.

\subsection{Simulation of ENSO precipitation anomalies}

The ENSO phenomenon has been shown to be a major driver of tropical climate variability (Trenberth et al. 1998, Shukla 2000). ENSO events, consisting of a warm anomaly in the winter SST patterns over the eastern equatorial Pacific, occur at a frequency of about 2 to 6 yr. During our simulated time period (1998-2002) a major ENSO event took place in the winter of 1998, perhaps the most intense on record in the 20th century (Fedorov \& Philander 2000, Wang \& Picaut 2004). Conversely, the winter of 2000 was characterized by the opposite (La Niña) SST conditions (see for example www.aoml.noaa.gov/phod/ regsatprod/enso/enso34/sst_ts.php). Our simulation period thus includes both an El Niño and a La Niña event, which are indeed well represented in the observed SST dataset used to drive the RegT-Band model. Fig. 12a depicts the difference in SST between the El Niño of 1998 and La Niña of 2000 used 


\section{HadISST1}
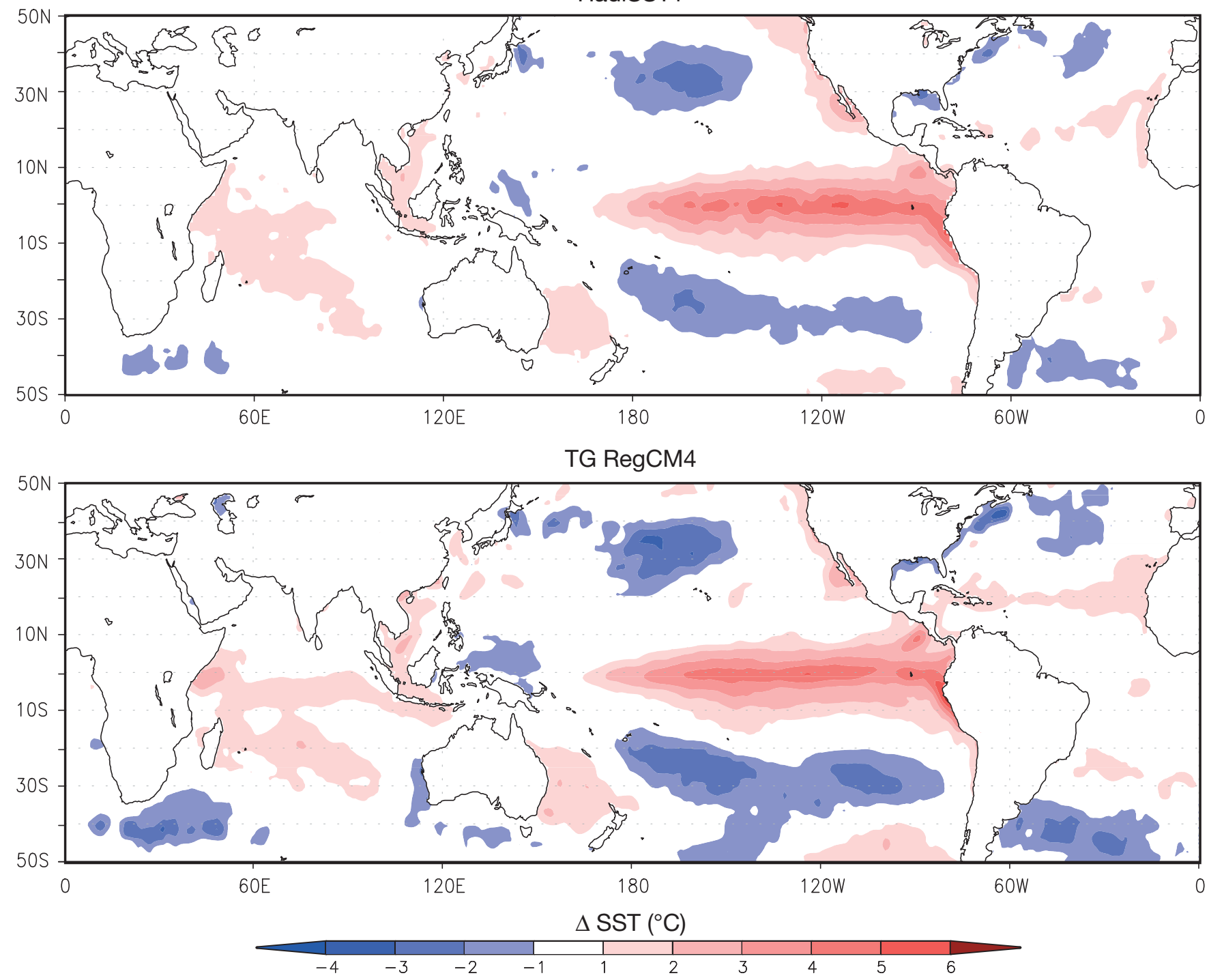

Fig. 12. Difference in January-February-March (JFM) SST $\left({ }^{\circ} \mathrm{C}\right)$ between the 1998 El Niño and 2000 La Niña events for observations (upper panel) and model (lower panel)

in the model, showing a marked warm anomaly of up to a several degrees over the central and eastern equatorial Pacific, with cold anomalies to the south and north of the area.

Although ensemble simulations may be necessary to capture the atmospheric response to ENSO (Shukla 2000), given the magnitude of the events mentioned above, it is possible that even individual realizations, such as completed here, may capture the first-order precipitation response to ENSO anomalies. Based on these considerations, Fig. 13 presents the difference in January-February-March (JFM) precipitation and surface wind between the 1998 El Niño and 2000 La Niña years in the RegT-Band, TRMM and GPCP observations.
In terms of the El Niño response, both TRMM and GPCP show a band of positive precipitation anomaly across the equatorial Pacific, with bands of negative anomaly north and south of it in the central and western Pacific. This pattern, which is one of the leading precipitation responses to El Niño (e.g. Ropelewski \& Halpert 1987, Trenberth et al. 1998, Yadav et al. 2010), is well captured by the model and is due to the response of convection to the Pacific SST anomalies (Fig. 13). Both the observations and the model show a negative precipitation anomaly over the Atlantic, while more mixed signals are found over the Indian Ocean. The wind anomaly shows convergence patterns consistent with the precipitation anomalies. 
RegCM4

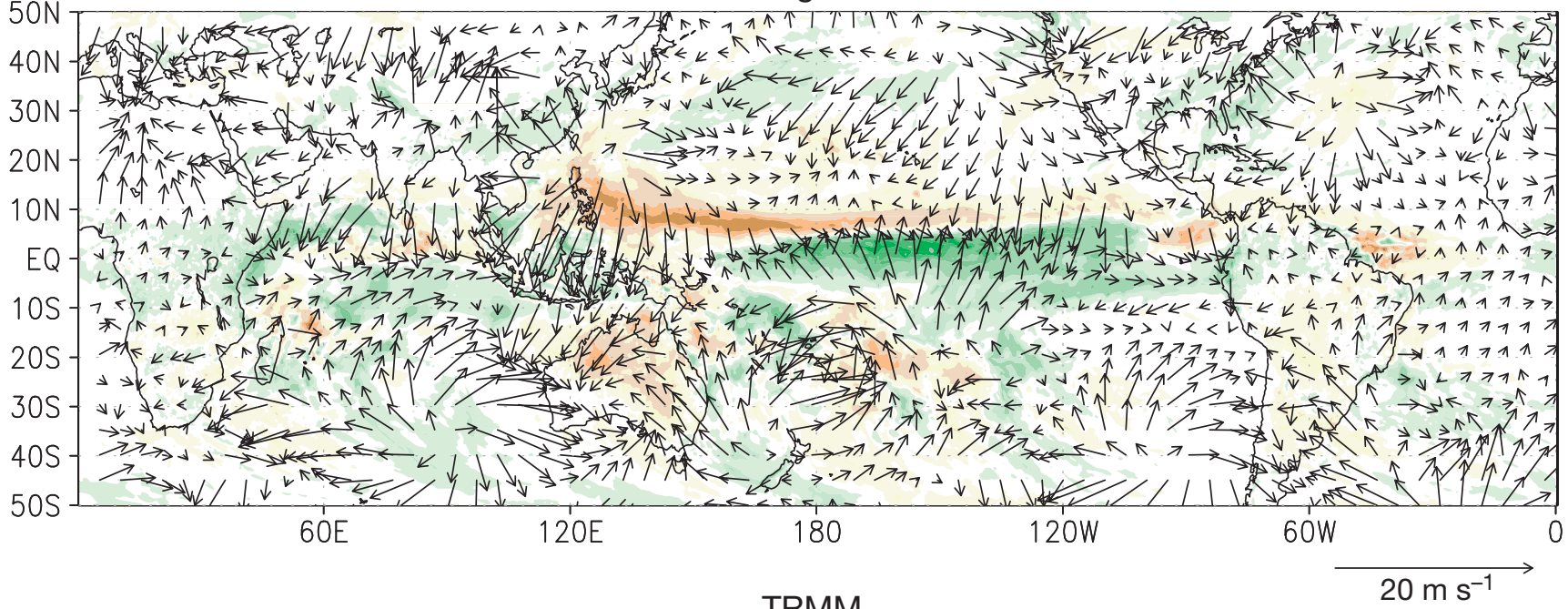

TRMM
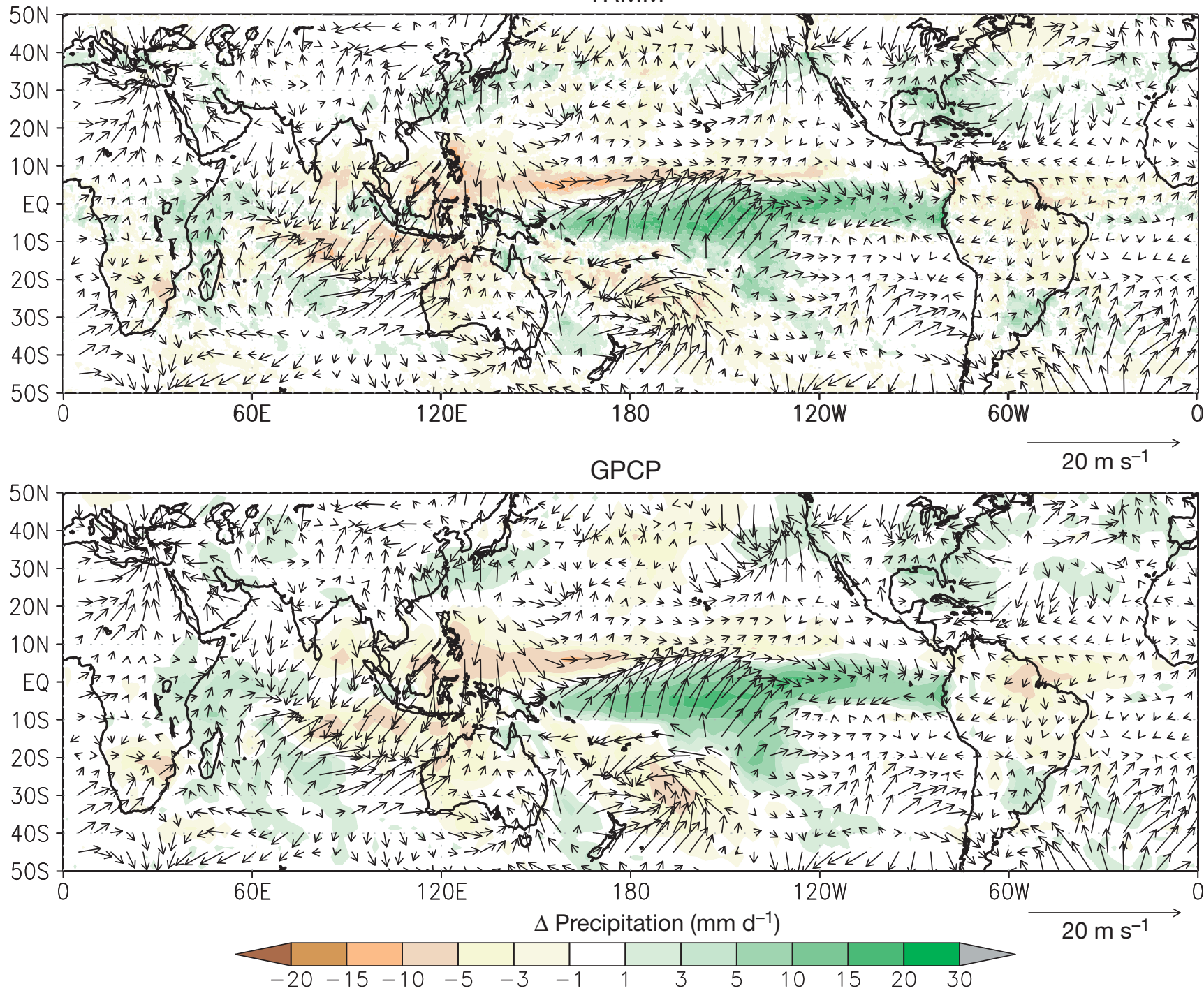

Fig. 13. Difference in JFM precipitation $\left(\mathrm{mm} \mathrm{d}^{-1}\right)$ and surface wind between the $1998 \mathrm{El}$ Niño and 2000 La Niña events in RegT-band, TRMM and GPCP 


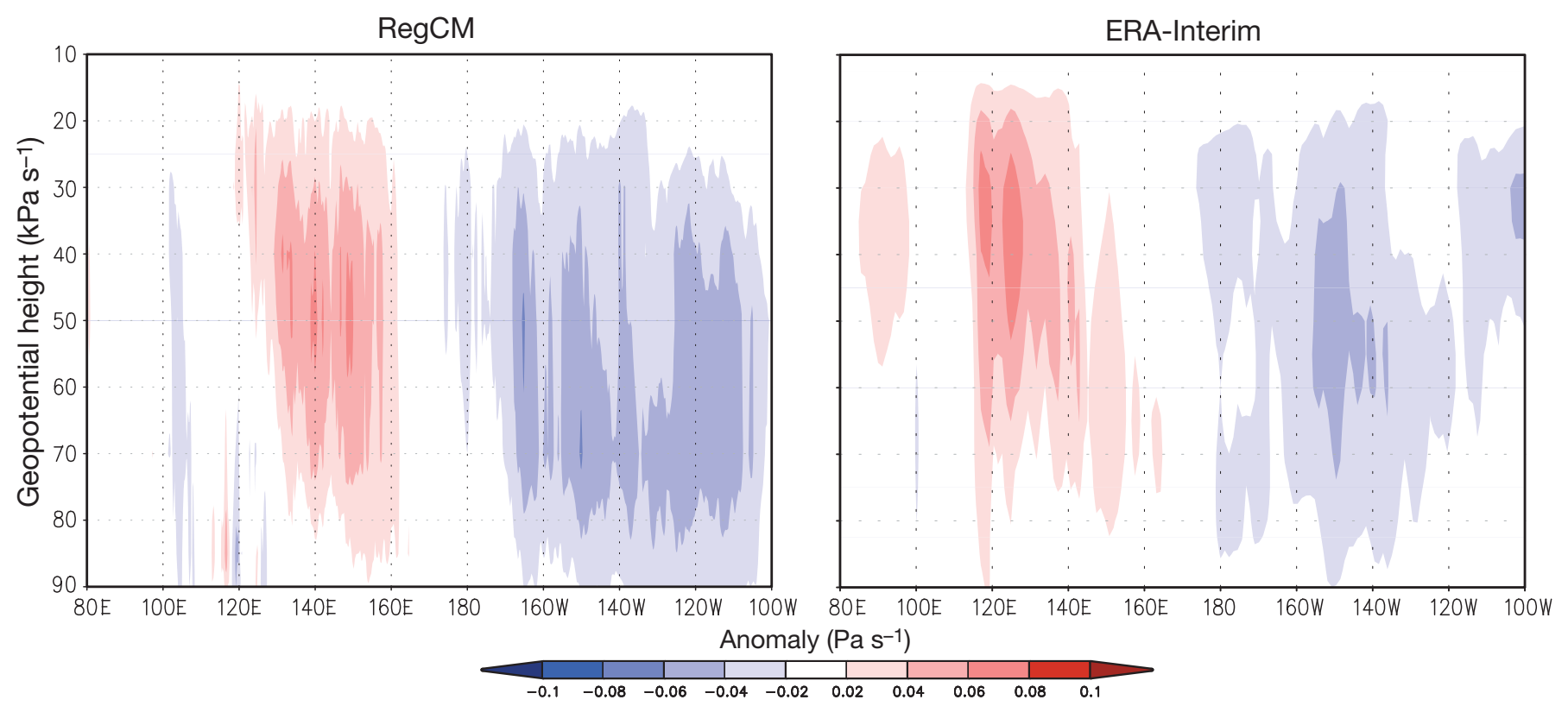

Fig. 14. Meridional anomaly for the omega (dp/dt) cross section $\left(\mathrm{Pa} \mathrm{s}^{-1}\right.$ ) (averaged between $10^{\circ} \mathrm{N}$ and $10^{\circ} \mathrm{S}$ ) for $\mathrm{JFM}$ in RegT-Band and ERA-Interim

Moving to the land precipitation response, in the observation products we find positive anomalies over eastern Africa, East China, the southeastern United States and the lower La Plata River basin. These are also consistent with the leading precipitation response to El Niño anomalies (Ropelewski \& Halpert 1987, Trenberth et al. 1998) and are captured by the model, except for the anomaly over the La Plata basin, which shows a more mixed signal in the model. Observed negative anomalies are found over Australia, southern Africa and large parts of the Amazon basin. These are also by-and-large captured by the model, although with varying degrees of agreement with observations in terms of local detail. The only substantial disagreement between the model and observations occurs over the Maritime Continent, where the observations show a negative precipitation anomaly. To further investigate the reason for the disagreement, the vertical velocity anomaly field across the Pacific is reported in Fig. 14. Overall the Walker circulation anomaly is well reproduced by the RegT-Band, the only region where the model shows a different signal is between $80^{\circ}$ and $100^{\circ} \mathrm{E}$, where the reanalysis has a descending vertical velocity anomaly that is not reproduced by the model.

Fig. 15 shows the Hovmoller diagrams for the 2 different years. In 1998 the model is able to capture the precipitation response connected with the positive El Niño phase. The location of the precipitation anomaly is slightly moved to the north compared to observations, but the timing of the event is correctly simulated for both El Niño and la Niña events.
In summary, despite the completion of a single realization including a single ENSO event, our results indicate that the model is capable of capturing the first-order precipitation response to ENSO anomalies.

\section{CONCLUSIONS}

One of the important capabilities of the newly developed regional climate modeling system RegCM4 is the possibility to run the model in tropical band mode, which we refer to as RegT-Band. In the current paper we present a first assessment of a 5 yr simulation of this model configuration at a horizontal grid spacing of $\sim 39 \mathrm{~km}$. The analysis presented here indicates that the model reproduces the basic characteristics of the tropical circulation and surface climate, although with some systematic biases compared to observations, particularly over the Indian Ocean. This is an especially difficult region to simulate in atmosphere-only models due to the strong coupling with the ocean dynamics (e.g. Ratnam et al. 2009).

Although for this run we selected a particular set of physics schemes after several short sensitivity tests, the RegCM4 model is sensitive to the choice of physics parameterizations, in particular for convection and land surface (Giorgi et al. 2012). For example, we have found that Indian Ocean precipitation is indeed sensitive to the use of the Grell versus the Emanuel scheme (L. Mariotti pers. comm.). Often, however, different schemes show varying performances over different regions of the tropics, and it is 

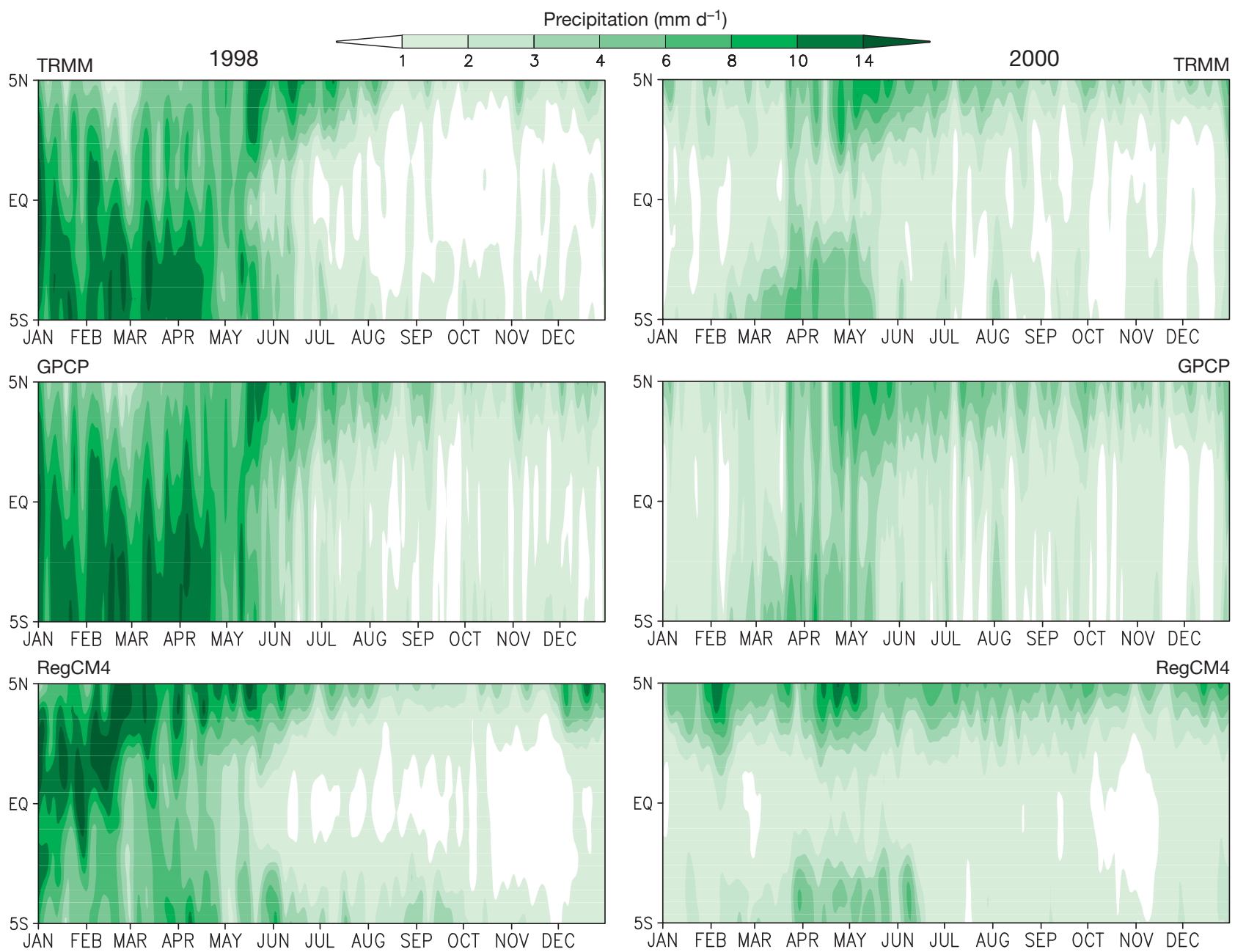

Fig. 15. Hovmoller precipitation diagrams (1998 and 2000) over the El Niño 3.4 region. Upper panels are for TRMM, midpanels are for GPCP and lower panels are for RegT-Band

thus a very complex, time-consuming and resourceintensive task to select a configuration that ubiquitously shows the best performance.

We are in the process of analyzing further aspects of the simulation, such as the simulation of tropical storms and the Madden-Julian Oscillation, as well as testing different model options and configurations further. Despite this ongoing process, the results presented here are clearly encouraging towards the use of the RegT-Band configuration for studies of tropical climate processes. We emphasize again that in its tropical band configuration, the RegCM system mostly behaves as a global model; thus, RegT-band offers the opportunity of a more stringent assessment of model behavior. We are indeed planning to employ the RegT-band model for climate change simulations, studies of tropical processes and as a test bed for comparing corresponding experiments with limited area domains.

\section{LITERATURE CITED}

Biasutti M, Battisti DS, Sarachik ES (2003) The annual cycle over the tropical Atlantic, South America, and Africa. J Clim 16:2491-2508

Collier JC, Bowman KP (2004) Diurnal cycle of tropical precipitation in a general circulation model. J Geophys Res 109:D17105. doi:10.1029/2004JD004818

Dai A, Trenberth KE (2004) The diurnal cycle and its depiction in the community climate system model. J Clim 17: 930-951

Davis N, Bowden JH, Semazzi FHM, Xie L, Onol B (2009) Customization of RegCM3 regional climate model for eastern Africa and tropical Indian ocean domain. J Clim 22:3595-3616

Dickinson RE, Henderson-Sellers A, Kennedy P (1993) Biosphere-atmosphere transfer scheme (BATS) Version 1e as coupled to the NCAR community climate model. Tech Rep, National Center for Atmospheric Research Tech Note TN-387+STR, NCAR, Boulder, CO

Diro GT, Rauscher SA, Giorgi F, Tompkins AM (2012) Sensitivity of seasonal climate and diurnal precipitation over Central America to land and sea surface schemes in 
RegCM4. Clim Res 52:31-48

Emanuel KA (1991) A scheme for representing cumulus convection in large-scale models. J Atmos Sci 48:2313-2335

Fedorov A, Philander SG (2000) Is El Niño changing? Science 288:1997-2002

Giannini A, Saravanan R, Chang P (2003) Oceanic forcing of Sahel rainfall on an interannual to interdecadal time scale. Science 302:1027-1030

> Giorgi F, Marinucci MR, Bates G, DeCanio G (1993) Development of a second generation regional climate model (RegCM2). II. convective processes and assimilation of lateral boundary conditions. Mon Weather Rev 121: 2814-2832

Giorgi F, Bi X, Pal JS (2004) Mean, interannual variability and trends in a regional climate change experiment over Europe. I. present day climate (1961-1990). Clim Dyn 22: 733-756

Giorgi F, Jones C, Asrar G (2009) Addressing climate information needs at the regional level: the CORDEX framework. WMO Bull 58:175-183

Giorgi F, Coppola E, Solmon F, Mariotti L and others (2012) RegCM4: model description and preliminary tests over multiple CORDEX domains. Clim Res 52:7-29

Grell GA (1993) Prognostic evaluation of assumptions used by cumulus parameterizations. Mon Weather Rev 121: 764-787

> Holtslag A, de Bruijn E, Pan HL (1990) A high resolution air mass transformation model for short-range weather forecasting. Mon Weather Rev 118:1561-1575

Huffman GJ, Adler RF, Morrissey MM, Bolvin DT and others (2001) Global precipitation at one-degree daily resolution from multi-satellite observations. J Hydrometeorol 2: $36-50$

Huffman GJ, Bolvin DT, Nelkin EJ, Wolff DB and others (2007) The TRMM multisatellite precipitation analysis (TMPA): quasi-global, multiyear, combined-sensor precipitation estimates at fine scale. J Hydrometeorol 8: 38-55

Ju J, Slingo JM (1995) The Asian summer monsoon and ENSO. Q J R Meteorol Soc 121:1133-1168

Kiehl J, Hack JJ, Bonan GB, Boville BA, Breigleb BP, Williamson DL, Rasch PJ (1996) Description of the NCAR community climate model (CCM3). Technical Note NCAR/TN-420+STR, National Center for Atmospheric Research, Boulder, CO

Kummerow C, Hong Y, Olson WS, Yang S and others (2001) The evolution of the Goddard profiling algorithm (GPROF) for rainfall estimation from passive microwave sensors. J Appl Meteorol 40:1801-1840

Madden RA, Julian PR (1972) Description of global-scale circulation cells in the tropics with a 4050-day period. J Atmos Sci 29:11091123

Mariotti L, Coppola E, Sylla MB, Giorgi F, Piani C (2011) Regional climate model simulation of projected 21st century climate change over an all-Africa domain: comparison analysis of nested and driving model results. J Geophys Res 116:D15111. doi:10.1029/2010JD015068

Submitted: May 30, 2011; Accepted: December 13, 2011
Mitchell TD, Carter TR, Jones PD, Hulme M, New M (2004) A comprehensive set of high-resolution grids of monthly climate for Europe and the globe: the observed record, 1901-2000: and 16 scenarios, 2001-2100. Working Paper 55, Tyndall Centre for Climate Change Research, Norwich

Murthi A, Bowman KP, Leung LR (2011) Simulations of precipitation using NRCM and comparisons with satellite observations and CAM: annual cycle. Clim Dyn 36: 1659-1679

Pal JS, Giorgi F, Bi X, Elguindi N and others (2007) Regional climate modeling for the developing world: the ICTP RegCM3 and RegCNET. Bull Am Meteorol Soc 88: 1395-1409

Pal JS, Small E, Eltahir E (2000) Simulation of regional-scale water and energy budgets: representation of subgrid cloud and precipitation processes within RegCM. J Geophys Res 105:29579-29594

Ratnam JV, Giorgi F, Kaginalkar A, Cozzini S (2009) Simulation of the Indian monsoon using the RegCM3-ROMS regional coupled model. Clim Dyn 33:119-139

Rauscher SA, Kucharski F, Enfield DB (2010) The role of regional SST warming variations in the drying of Meso-America in future climate projections. J Clim 24: 2003-2016

Ray P, Zhang C, Moncrieff MW, Didhia J and others (2011) Role of the atmospheric mean state on the initiation of the Madden Julian oscillation in a tropical channel model. Clim Dyn 36:161-184

Reynolds RW, Rayner NA, Smith TM, Stokes DC, Wang W (2002) An improved in situ and satellite SST analysis for climate. J Clim 15:1609-1625

> Ropelewski CF, Halpert MS (1987) Global and regional scale precipitation patterns associated with the El Niño/ Southern Oscillation (ENSO). Mon Weather Rev 115: 1606-1626

Shukla J (2000) Dynamical seasonal prediction. Bull Am Meteorol Soc 81:2593-2606

> Trenberth KE, Branstator GW, Karoly D, Kumar A, Lau NC, Ropelewski C (1998) Progress during TOGA in understanding and modeling global teleconnections associated with tropical sea surface temperatures. J Geophys Res 103:14,291-14,324

- Tulich SN, Kiladis GN, Parker AS (2010) Convectivelycoupled Kelvin and easterly waves in a regional climate simulation of the tropics. Clim Dyn 36:185-203

Uppala S, Dee D, Kobayashi S, Berrisford P, Simmons A (2008) Towards a climate adapt assimilation system: status update of ERA-Interim. ECMWF Newsletter 115:12-18

Wang C, Picaut J (2004) Understanding ENSO physicsa review. In: Wang $\mathrm{C}$, Xie SP, Carton JA (eds) Earth's climate: the ocean-atmosphere interaction. AGU Geophys Monogr Ser 147:21-48

Yadav RK, Yoo JH, Kucharski F, Abid MA (2010) Why is ENSO influencing Northwest India winter precipitation in recent decades? J Clim 23:1979-1993

> Yang GY, Slingo J (2001) The diurnal cycle in the tropics. Mon Weather Rev 129:784-801

Proofs received from author(s): March 1, 2012 